Supplement of The Cryosphere, 14, 3707-3729, 2020

https://doi.org/10.5194/tc-14-3707-2020-supplement

(C) Author(s) 2020. This work is distributed under

the Creative Commons Attribution 4.0 License.

(c) (1)

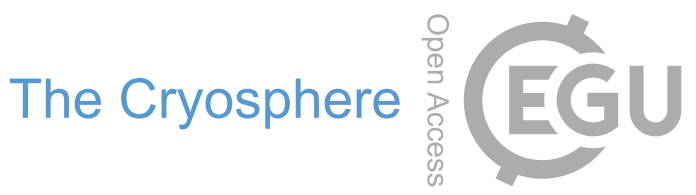

Supplement of

\title{
High-resolution simulations of interactions between surface ocean dynamics and frazil ice
}

\author{
Agnieszka Herman et al. \\ Correspondence to: Agnieszka Herman (oceagah@ug.edu.pl)
}

The copyright of individual parts of the supplement might differ from the CC BY 4.0 License. 


\section{Section S1. Ocean-atmosphere fluxes}

In all formulae below, temperature is expressed in degrees Celsius and salinity in PSU.

The saturation vapor pressure over sea water with surface salinity $S_{0}, e_{s}=e_{s}\left(T, S_{0}\right)$ is computed from:

$$
e_{s}\left(T, S_{0}\right)=6.1378 \beta_{S}\left(S_{0}\right) \exp \left[\frac{17.502 T}{240.97+T}\right], \quad \text { with } \quad \beta_{S}\left(S_{0}\right)=\left(1.0-5.37 \cdot 10^{-4} S_{0}\right) .
$$

The relationships between vapor pressure $e$, mixing ratio $r$, specific humidity $q$, and relative humidity $r_{\text {rel }}$ are:

$$
\begin{aligned}
r(e) & =\frac{0.62197 e}{p-e}=r_{\mathrm{rel}} r\left(e_{s}\right), \\
q & =\frac{r}{1+r},
\end{aligned}
$$

where $p$ denotes atmospheric pressure.

As stated in the main text, the ocean-atmosphere fluxes are computed from the following input variables: surface water temperature $T_{w}$, surface salinity $S_{0}$, sea level pressure $p_{a}$, air temperature $T_{a}$, relative humidity $r_{\text {rel }}$, and wind speed $U_{a}$. The air density $\rho_{a}$ and the heat of evaporation $L_{e}$ are computed from:

$$
\begin{aligned}
\rho_{a} & =0.34838 \frac{p_{a}(1.0+r)}{\left(T_{a}+273.16\right)(1.0+1.60779 r)}, \\
L_{e} & =2.5029 \cdot 10^{6}-2.40 \cdot 10^{3} T_{w}
\end{aligned}
$$

and the specific heat of air and water are assumed constant, respectively, $c_{p, a}=1004.8 \mathrm{~J} \cdot \mathrm{kg}^{-1} \cdot \mathrm{K}^{-1}$ and $c_{p, w}=3985 \mathrm{~J} \cdot \mathrm{kg}^{-1} \cdot \mathrm{K}^{-1}$.

The transfer coefficients for momentum, sensible and latent heat, $C_{d}, C_{h}$ and $C_{e}$, are computed as:

$$
\begin{aligned}
C_{d} & =C_{d, n} \alpha_{s}, \\
C_{h} & =C_{h, n} \alpha_{s}, \\
C_{e} & =C_{e, n} \alpha_{s},
\end{aligned}
$$

where $C_{d, n}, C_{h, n}$ and $C_{e, n}$ are transfer coefficients under neutral conditions, and $\alpha_{s}$ is a stability parameter, given by:

$$
\alpha_{s}= \begin{cases}0.1+0.03 s+0.9 \exp [4.8 s] & \text { for } \quad s \leq 0 \\ 1.0+0.63 s^{1 / 2} & \text { for } \quad s>0\end{cases}
$$

with

$$
\begin{aligned}
s & =\max \left\{-3.3, \frac{s_{0}\left|s_{0}\right|}{\left|s_{0}\right|+0.01}\right\}, \\
s_{0} & =\frac{T_{w}-T_{a}}{U_{0}^{2}} \\
U_{0} & =\max \left\{0.1, U_{a}\right\}
\end{aligned}
$$

(see Appendix 3 in Kondo, 1975).

In the bulk formulae implemented in the original code of CROCO, constant values of the neutral coefficients are used, $C_{h, n}=0.0011$ and $C_{d, n}=C_{e, n}=0.0014$. However, under highly unstable conditions of interest in this work $\left(T_{a} \ll T_{w}\right)$, formulae (6)-(12) with constant neutral coefficients lead to transfer coefficients decreasing with increasing wind speed, which is contrary to observations (for $T_{a} \geq T_{w}$ the behavior is correct). Therefore, the original formulae of Kondo (1975) are preferred. However, they are formulated for five wind speed intervals (dashed lines in Fig. S1a), which makes them unattractive computationally (several 'if' commands necessary in the code). Therefore, approximate formulae are used here, obtained as the following least-square fits to Kondo's expressions:

$$
\begin{aligned}
10^{3} C_{d, n} & =\max \left\{a_{d} U_{a}^{b_{d}}, 1.0\right\}, \\
10^{3} C_{h, n} & =\max \left\{\left(a_{h} U_{a}+b_{h}\right) /\left(U_{a}^{2}+c_{h} U_{a}+d_{h}\right), 1.05\right\}, \\
10^{3} C_{e, n} & =\max \left\{\left(a_{e} U_{a}+b_{e}\right) /\left(U_{a}^{2}+c_{e} U_{a}+d_{e}\right), 1.1\right\},
\end{aligned}
$$


(a)

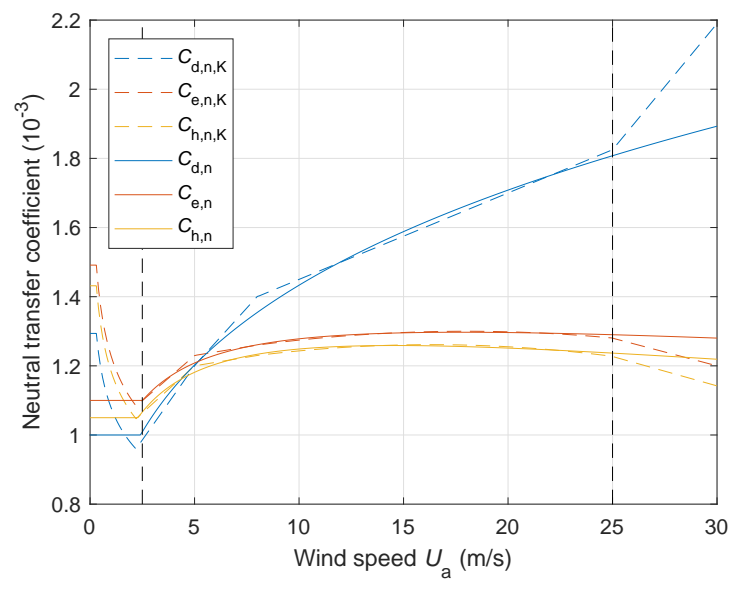

(c)

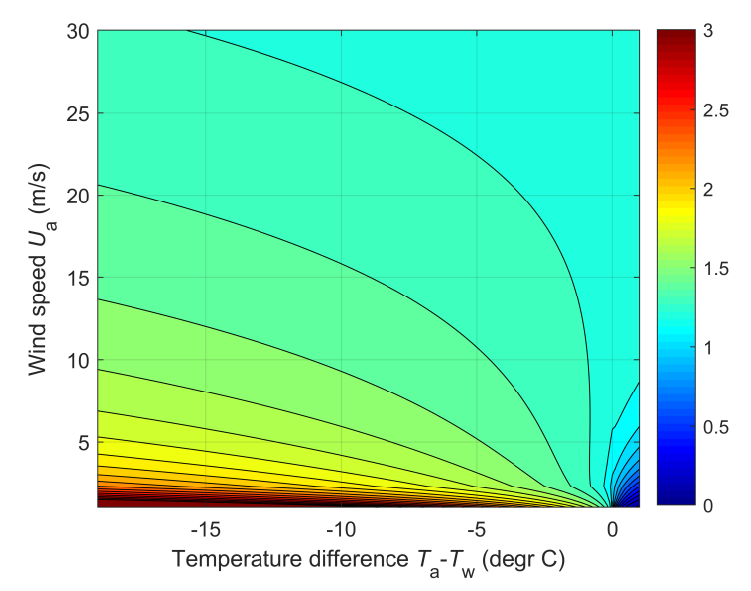

(b)

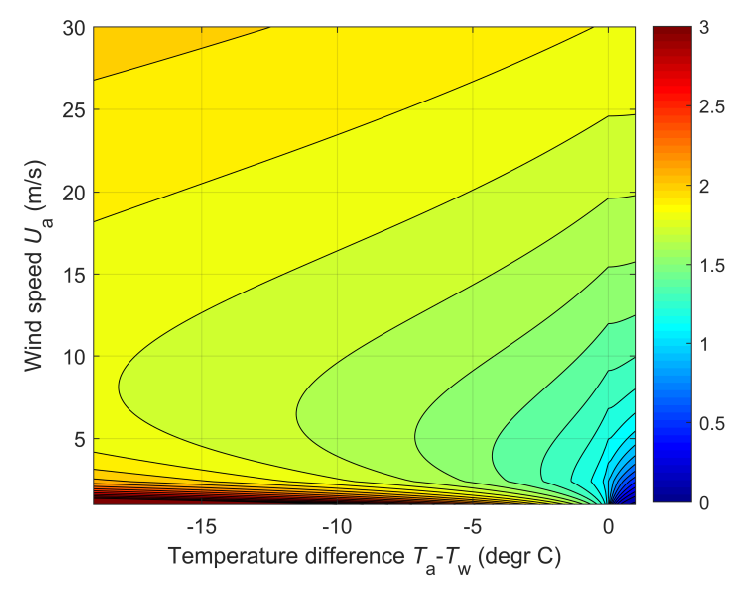

(d)

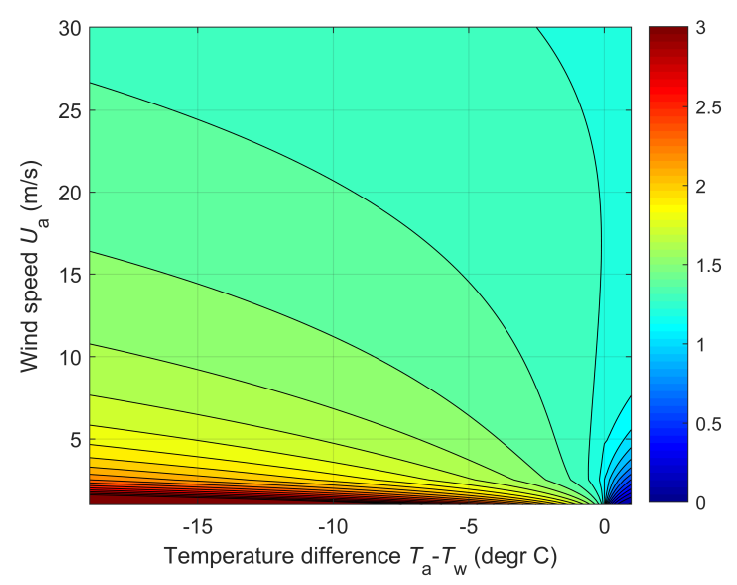

Figure S1: Transfer coefficients for momentum, sensible and latent heat fluxes: neutral coefficients $C_{d, n}$, $C_{h, n}, C_{e, n}$ in function of wind speed (a) and the "total" values $C_{d}$ (b), $C_{h}$ (c), $C_{e}$ (d) in function of air-water temperature difference and wind speed. Values in (b)-(d) are multiplied by $10^{3}$. In (a), dashed lines show the original formulae of Kondo (1975), and continuous lines the fitted formulae (13)-(15).

with $a_{d}=0.7997, b_{d}=0.2533, a_{h}=297.2, b_{h}=274.8, c_{h}=207.0, d_{h}=430.8, a_{e}=474.6, b_{e}=487.6$, $c_{e}=330.4, d_{e}=690.7$ (continuous lines in Fig. S1a). The resulting $C_{d}, C_{h}$ and $C_{e}$ for a range of $\left(T_{a}-T_{w}\right)$ and $U_{a}$ values are shown in Fig. S1b-d.

The wind stress $\tau_{w}$ (in $\mathrm{N} \cdot \mathrm{m}^{-2}$ ), the two components of the turbulent heat flux, $F_{h}$ and $F_{e}$ (in $\mathrm{W} \cdot \mathrm{m}^{-2}$ ), and the corresponding evaporation rate $H_{e}\left(\mathrm{in} \mathrm{kg} \cdot \mathrm{m}^{-2} \cdot \mathrm{s}^{-1}\right)$, are given by:

$$
\begin{aligned}
\tau_{w} & =\rho_{a} C_{d} U_{a}^{2}, \\
F_{h} & =-\rho_{a} c_{p, a} C_{h} U_{a}\left(T_{w}-T_{a}\right) \\
F_{e} & =-\rho_{a} L_{e} C_{e} U_{a}\left(q_{s, w}-q_{a}\right), \\
H_{e} & =\rho_{a} C_{e} U_{a}\left(q_{s, w}-q_{a}\right),
\end{aligned}
$$

where $q_{a}$ is the specific humidity of the air and $q_{s, w}$ is the saturation specific humidity at temperature $T_{w}$. The heat fluxes are negative when the ocean loses heat to the atmosphere. The values of $\tau_{w}, F_{h}$ and $F_{e}$ for a range of $\left(T_{a}-T_{w}\right)$ and $U_{a}$ values are shown in Fig. S2a,c,d.

The net long-wave radiation at the sea surface, $F_{\text {rad }}$, is computed as:

$$
F_{\mathrm{rad}}=\varepsilon \sigma_{S B}\left[\left(T_{a}+273.16\right)^{4}-\left(T_{w}+273.16\right)^{4}\right],
$$


(a)

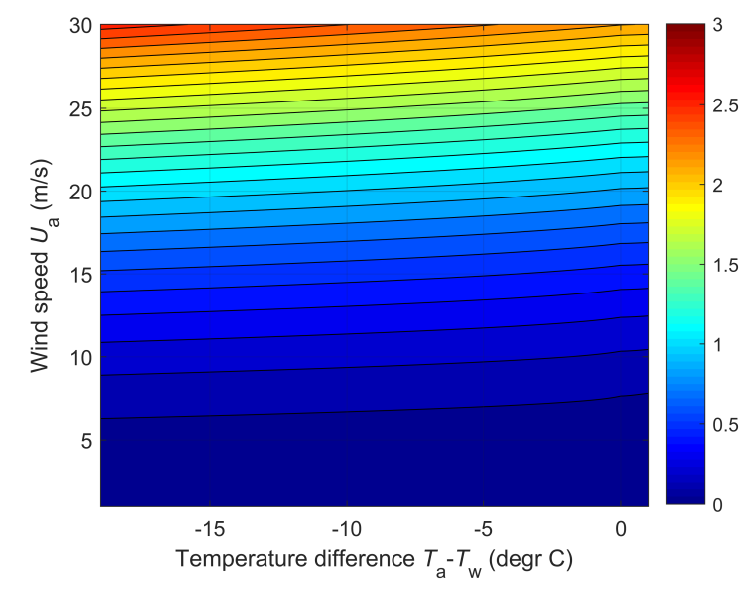

(c)

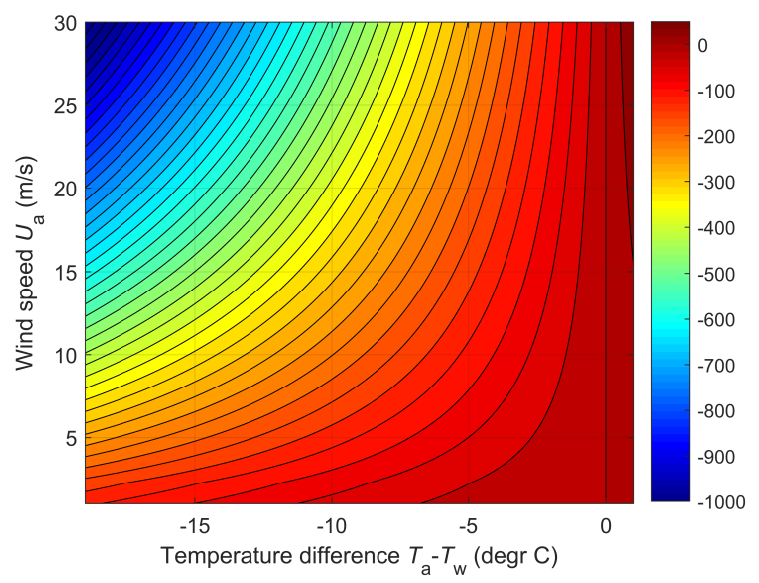

(b)

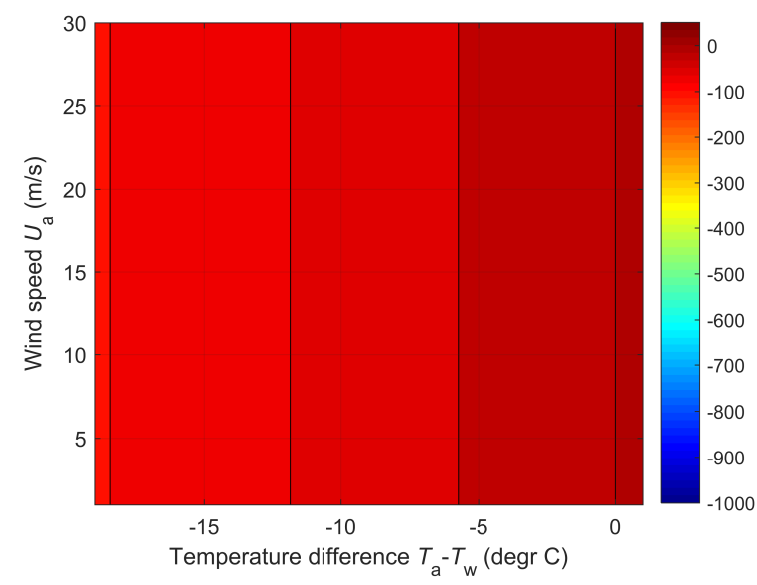

(d)

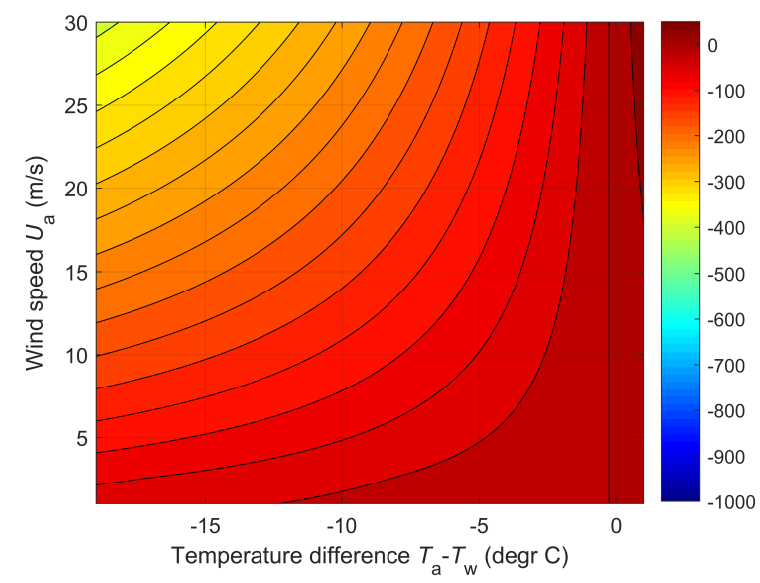

Figure S2: Wind stress on the sea surface $\tau_{w}\left(\mathrm{a} ;\right.$ in $\left.\mathrm{N} \cdot \mathrm{m}^{-2}\right)$ and the three components of surface heat flux $\left(\mathrm{b}-\mathrm{d}\right.$; in $\left.\mathrm{W} \cdot \mathrm{m}^{-2}\right): F_{\mathrm{rad}}(\mathrm{b}), F_{h}(\mathrm{c})$ and $F_{e}(\mathrm{~d})$. The color scales in (b)-(d) are the same. The contour distances equal $0.1 \mathrm{~N} \cdot \mathrm{m}^{-2}$ in (a) and $25 \mathrm{~W} \cdot \mathrm{m}^{-2}$ in (b)-(d).

where $\sigma_{S B}=5.6697 \cdot 10^{-8} \mathrm{~W} \cdot \mathrm{m}^{-2} \cdot \mathrm{K}^{-4}$ is the Stefan-Boltzmann constant and $\varepsilon=0.985$ is the emissivity (Fig. S2b).

Finally, the total net heat flux at the surface $F_{\text {net }}$ is:

$$
F_{\text {net }}=F_{\text {rad }}+F_{e}+F_{h}
$$

(short-wave radiation is not considered in this study). 


\section{Section S2. Estimation of relevant velocity scales}

As described in the main text, the three velocity scales relevant for the OML analyzed here are:

- friction velocity $u_{*}$,

- vertical velocity related to convective motion $w_{*}$ (Deardorff's velocity scale),

- vertical velocity related to the Langmuir turbulence $w_{*, L}$.

The friction velocity $u_{*}$ can be computed from $\tau_{w}$, obtained with (16) as described in Section S1:

$$
u_{*}=\left(\tau_{w} / \rho_{w}\right)^{1 / 2} .
$$

For the range of $T_{a}-T_{w}$ and $U_{a}$ considered here, the resulting values of $u_{*}$ are shown in Fig. S3.

The Deardorff's velocity scale $w_{*}$ is a function of the net buoyancy flux at the surface $B_{0}$ and the mixed layer depth $h$ :

$$
w_{*}=\left(B_{0} h\right)^{1 / 3},
$$

where $B_{0}$ is the sum of the thermal buoyancy $B_{T}$ and haline buoyancy $B_{S}$ :

$$
B_{0}=B_{T}+B_{S}=\frac{g}{\rho_{w}}\left(\frac{\beta_{T}}{c_{p, w}} F_{\mathrm{net}}+\beta_{S} S_{0} H_{e}\right),
$$

where $F_{\text {net }}$ and $H_{e}$ are computed from (21) and (19), respectively, and $\beta_{T}$ and $\beta_{S}$ are thermal expansion and saline contraction coefficients. Under conditions of interest, $B_{0}$ is dominated by the thermal component $B_{T}$. The resulting values of $B_{0}$ in function of $T_{a}-T_{w}$ and $U_{a}$ are shown in Fig. S4. The corresponding $w_{*}$ are shown in Fig. S5a,b for two arbitrarily selected values of $h, 10 \mathrm{~m}$ and $100 \mathrm{~m}$.

The third velocity scale, $w_{*, L}$, is given by:

$$
w_{*, L}=\left(u_{S} u_{*}^{2}\right)^{1 / 3},
$$

where $u_{S}=\left|\mathbf{u}_{S}\right|_{z=0}$ is the amplitude of the Stokes drift at the surface, dependent on wave amplitude $a$, frequency $\omega$ and wavenumber $k$ :

$$
u_{S}=\omega k a^{2}
$$

(monochromatic waves are assumed for simplicity). For deep water waves, for which $\omega^{2}=g k$ :

$$
u_{S}=g^{-1} \omega^{3} a^{2} .
$$

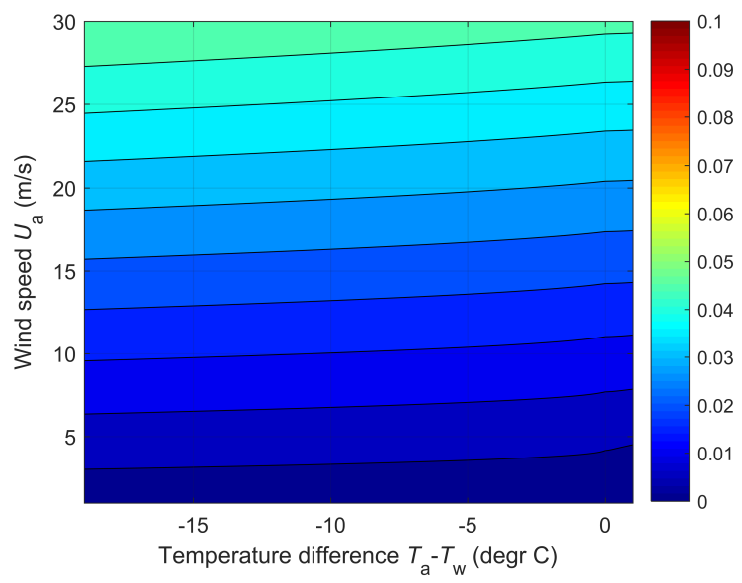

Figure S3: Friction velocity $u_{*}$ (in $\left.\mathrm{m} / \mathrm{s}\right)$. The color scale and contour interval $(0.005 \mathrm{~m} / \mathrm{s})$ are the same as in Fig. S5. 


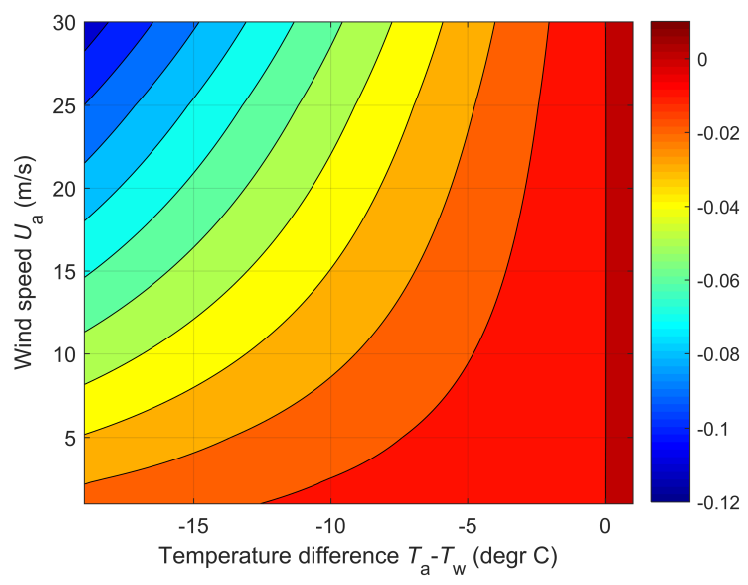

Figure S4: Buoyancy flux $B_{0}$ (in $10^{-6} \mathrm{~m}^{2} / \mathrm{s}^{3}$ ) computed from (24) for a range of $T_{a}-T_{w}$ and $U_{a}$ values.

Under assumptions described in the main text, i.e., for stationary, fetch-limited waves, the relevant wave parameters, i.e., significant wave height $H_{s}$ and peak period $T_{p}$, can be estimated based of fetch $X$ and wind speed $U_{a}$ by means of a simple statistical model. Krylov's model is used here, as described by Massel (2013), for which:

$$
\begin{aligned}
& H_{m}=0.16 \frac{U_{a}^{2}}{g}\left[1-\left(1+6 \cdot 10^{-3} \sqrt{\frac{g X}{U_{a}^{2}}}\right)^{-2}\right] \\
& T_{m}=19.478 \frac{U_{a}}{g}\left(\frac{g H_{m}}{U_{a}^{2}}\right)^{0.625} .
\end{aligned}
$$

Here, $H_{m}$ and $T_{m}$ are the mean wave height and period. Assuming $H_{s}=1.6 H_{m}$ and $T_{p}=1.25 T_{m}$ (Holthuijsen, 2007), as well as $a=H_{s} / 2$ and $\omega=2 \pi / T_{p}, u_{S}$ and thus $w_{*, L}$ can be computed for a given combination of $\left(T_{a}-T_{w}\right), U_{a}$ and $X$. The results are shown in Fig. S5c,d for two selected values of fetch, $100 \mathrm{~m}$ and $1000 \mathrm{~km}$ 
(a)

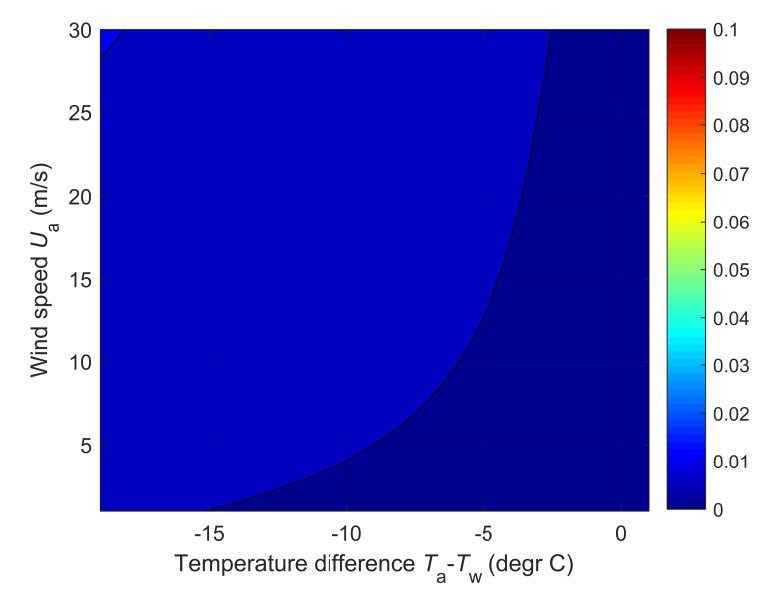

(c)

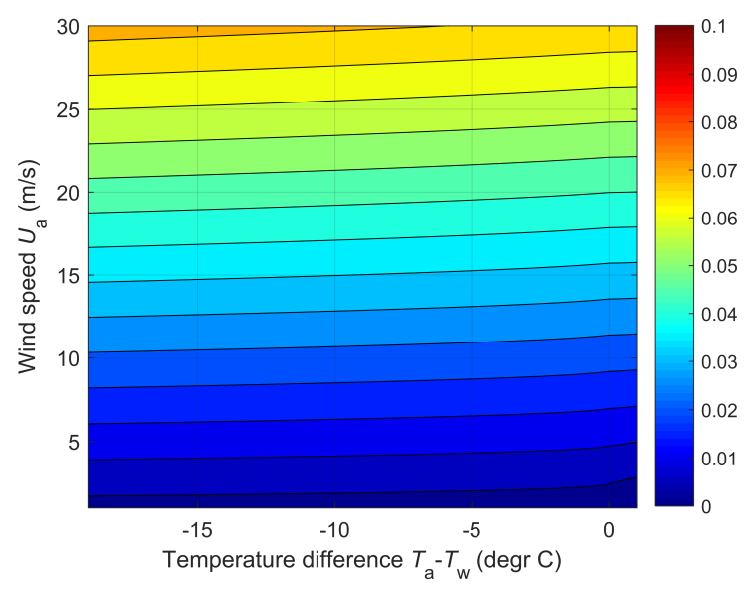

(b)

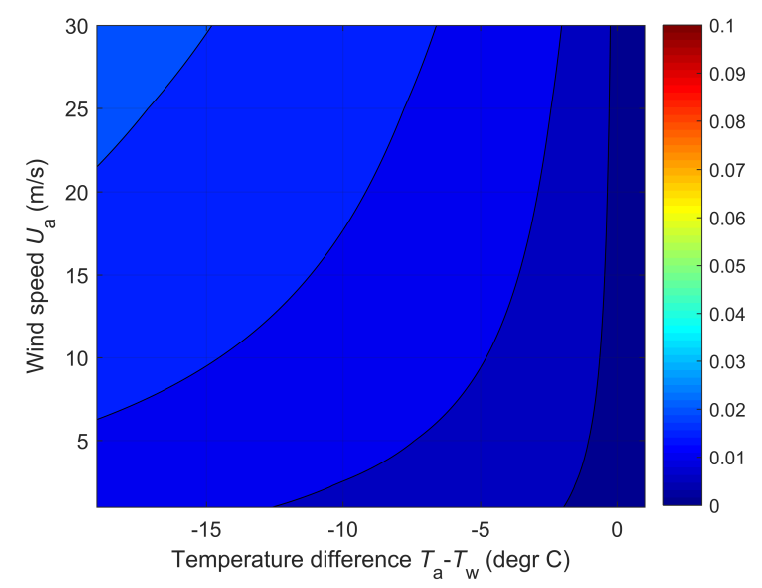

(d)

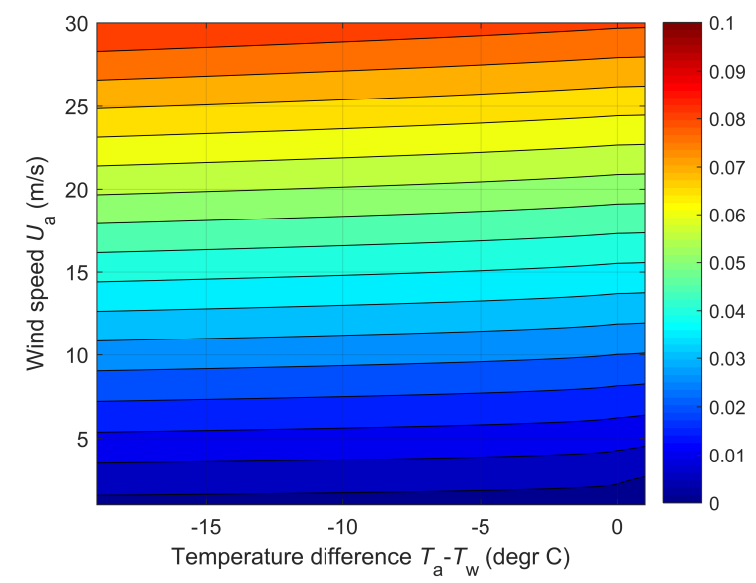

Figure S5: Velocity scales $w_{*}(\mathrm{a}, \mathrm{b})$ and $w_{*, L}(\mathrm{c}, \mathrm{d})$ in function of $T_{a}-T_{w}$ and $U_{a}$. Additional parameters: $h=10 \mathrm{~m}(\mathrm{a}), h=100 \mathrm{~m}(\mathrm{~b}), X=100 \mathrm{~m}(\mathrm{c}), X=1000 \mathrm{~km}$ (d). The color scale and contour interval $(0.005 \mathrm{~m} / \mathrm{s})$ are the same as in Fig. S3. 


\section{Section S3. Testing of the model}

\section{Turbulent Stokes-Ekman layer from McWilliams et al. (1997)}

The setup of this test case is described in detail in McWilliams et al. (1997) and Yang et al. (2015). A summary of the model settings is provided in Table S1. The prescribed wind stress corresponds to a wind speed of $\sim 5 \mathrm{~m} / \mathrm{s}$. The net surface heat flux has negligible effect on the model behavior and has been used by McWilliams et al. (1997) to facilitate model spin-up. The turbulent Langmuir number resulting from the combination of model parameters in this case $\mathrm{La}_{t}=0.3$.

Apart from the parameters listed in Table S1, all settings of the CROCO model were kept identical to those used in the main study (the turbulence model, non-hydrostatic mode, advection schemes, etc.). The model was run for $18 \mathrm{~h}$, and the results from a time period corresponding to one inertial period were used to compute vertical profiles of $\langle\bar{u}\rangle / u_{\star},\langle\bar{v}\rangle / u_{\star},\left\langle u^{\prime} w^{\prime}\right\rangle / u_{\star}^{2},\left\langle v^{\prime} w^{\prime}\right\rangle / u_{\star}^{2},\left\langle u^{\prime} u^{\prime}\right\rangle / u_{\star}^{2},\left\langle v^{\prime} v^{\prime}\right\rangle / u_{\star}^{2}$ and $\left\langle w^{\prime} w^{\prime}\right\rangle / u_{\star}^{2}$. In Figs. S6-S8 they are compared with analogous profiles obtained by McWilliams et al. (1997) and Yang et al. (2015). Additionally, in the case of $\left\langle w^{\prime} w^{\prime}\right\rangle / u_{\star}^{2}$, the results computed from in situ measurements in the open ocean by D'Asaro (2001) are shown (triangles in Fig. S8c), analyzed earlier by Yang et al. (2015) and Li et al. (2005).

In spite of several differences between the three models considered, the vertical profiles of both the mean velocity and velocity variance are comparable. The most pronounced difference between the results of CROCO and the other two models occurs for $\left\langle w^{\prime} w^{\prime}\right\rangle / u_{\star}^{2}$ : the maximum of $\left\langle w^{\prime} w^{\prime}\right\rangle / u_{\star}^{2}$ obtained with CROCO equals 1.98 and occurs at depth $z / h=-0.23$, i.e., it is smaller and located lower than the corresponding maxima in the two other studies $(2.78$ at $z / h=-0.14$ and 2.55 at $z / h=-0.18)$. Incidentally, the observed maximum of $\left\langle w^{\prime} w^{\prime}\right\rangle / u_{\star}^{2}$ from D'Asaro (2001), equal to 1.93, is very close to that from CROCO, although occurs slightly closer to the surface, at $z / h=-0.18$. As pointed out in the earlier studies, the value of the turbulent Langmuir number in the study by D'Asaro (2001) is not known, but their measurements were performed in the open ocean in fully developed wind seas, in which case $\mathrm{La}_{t}$ is close to 0.3, i.e., the value used in the simulations. The values of $\left\langle w^{\prime} w^{\prime}\right\rangle / u_{\star}^{2}$ produced by CROCO can be thus treated as realistic, although, in comparison to other models, CROCO tends to underestimate the amplitude of $\left\langle w^{\prime} w^{\prime}\right\rangle / u_{\star}^{2}$ and to overestimate its depth (the latter is also true for $\left\langle v^{\prime} w^{\prime}\right\rangle / u_{\star}^{2}$, see Fig. S7b).

Table S1: Setup of the CROCO model for the McWilliams et al. (1997) test case

\begin{tabular}{|l|c|}
\hline Parameter & Value \\
\hline Domain size $L_{x} \times L_{y} \times L_{z}$ & $150 \times 150 \times 90 \mathrm{~m}$ \\
Horizontal resolution $\Delta x$ & $3.0 \mathrm{~m}$ \\
Vertical resolution $\Delta z$ & $0.6 \mathrm{~m}$ \\
Time step $\Delta t$ & $0.1 \mathrm{~s}$ \\
\hline Surface wind stress in $x$ direction $\tau_{w, x}$ & $0.037 \mathrm{~N} \cdot \mathrm{m}^{-2}$ \\
Surface wind stress in $y$ direction $\tau_{w, y}$ & 0 \\
Surface heat flux $F_{\text {net }}$ & $-5 \mathrm{~W} \cdot \mathrm{m}^{-2}$ \\
Coriolis parameter $f$ & $1 \cdot 10^{-4} \mathrm{~s}^{-1}$ \\
Mixed layer depth $h$ & $33 \mathrm{~m}$ \\
Water temperature profile $T_{w}(z)$ & $T_{w}$ \\
& $T^{\circ} \mathrm{C} \mathrm{for} z \geq-h$ \\
Wave amplitude $a$ & $0.01(33+z)]^{\circ} \mathrm{C}$ for $z<-h$ \\
Wave period $T$ & $0.8 \mathrm{~m}$ \\
Wave direction $\theta$ relative to $\tau_{w, x}$ & $6.2 \mathrm{~s}$ \\
\hline
\end{tabular}



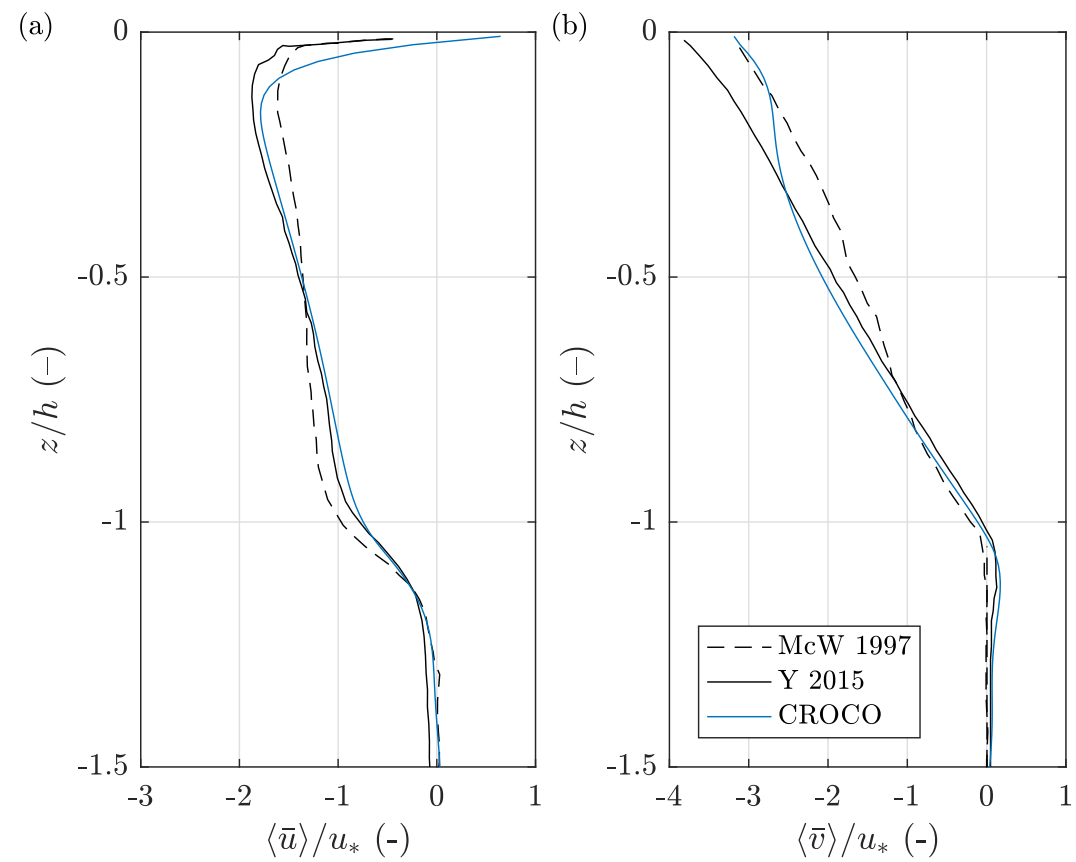

Figure S6: Time- and domain-averaged velocity profiles $\langle\bar{u}\rangle / u_{\star}$ (a) and $\langle\bar{v}\rangle / u_{\star}$ (b) obtained with CROCO (blue lines) and from the earlier studies by McWilliams et al. (1997) and Yang et al. (2015).
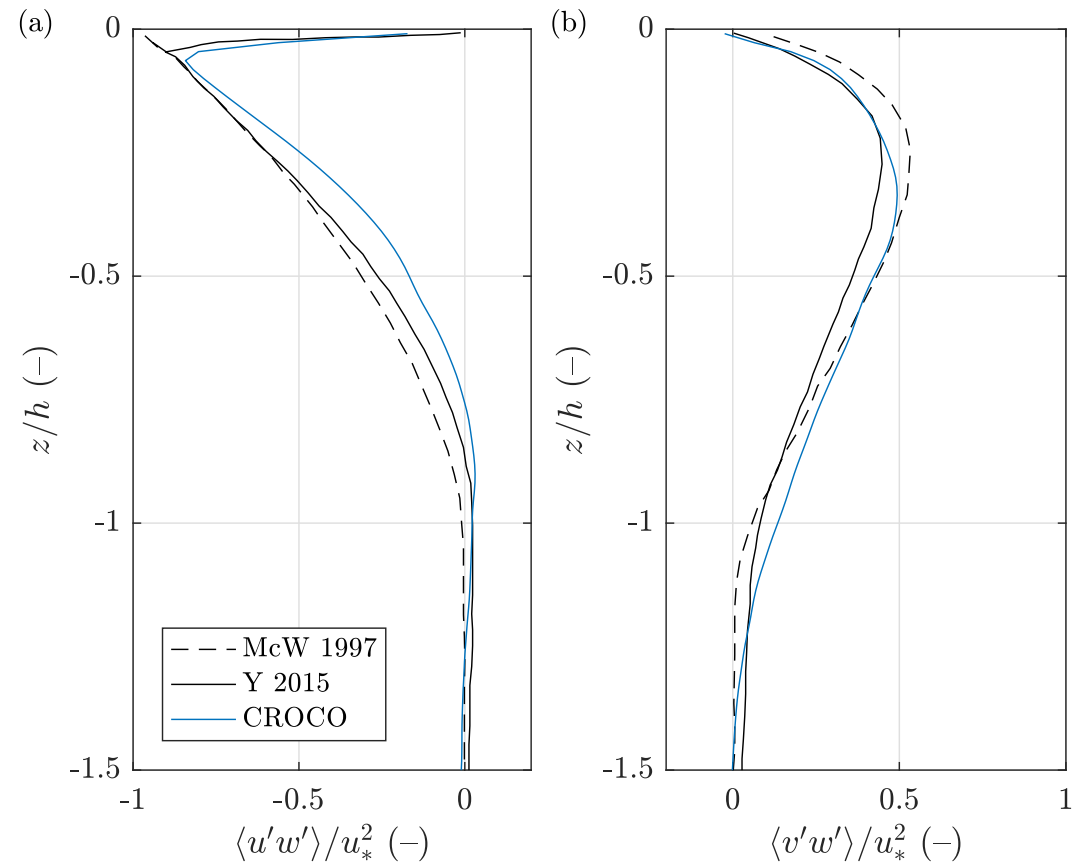

Figure S7: As in Fig. S6, but for $\left\langle u^{\prime} w^{\prime}\right\rangle / u_{\star}^{2}$ (a) and $\left\langle v^{\prime} w^{\prime}\right\rangle / u_{\star}^{2}$ (b). 

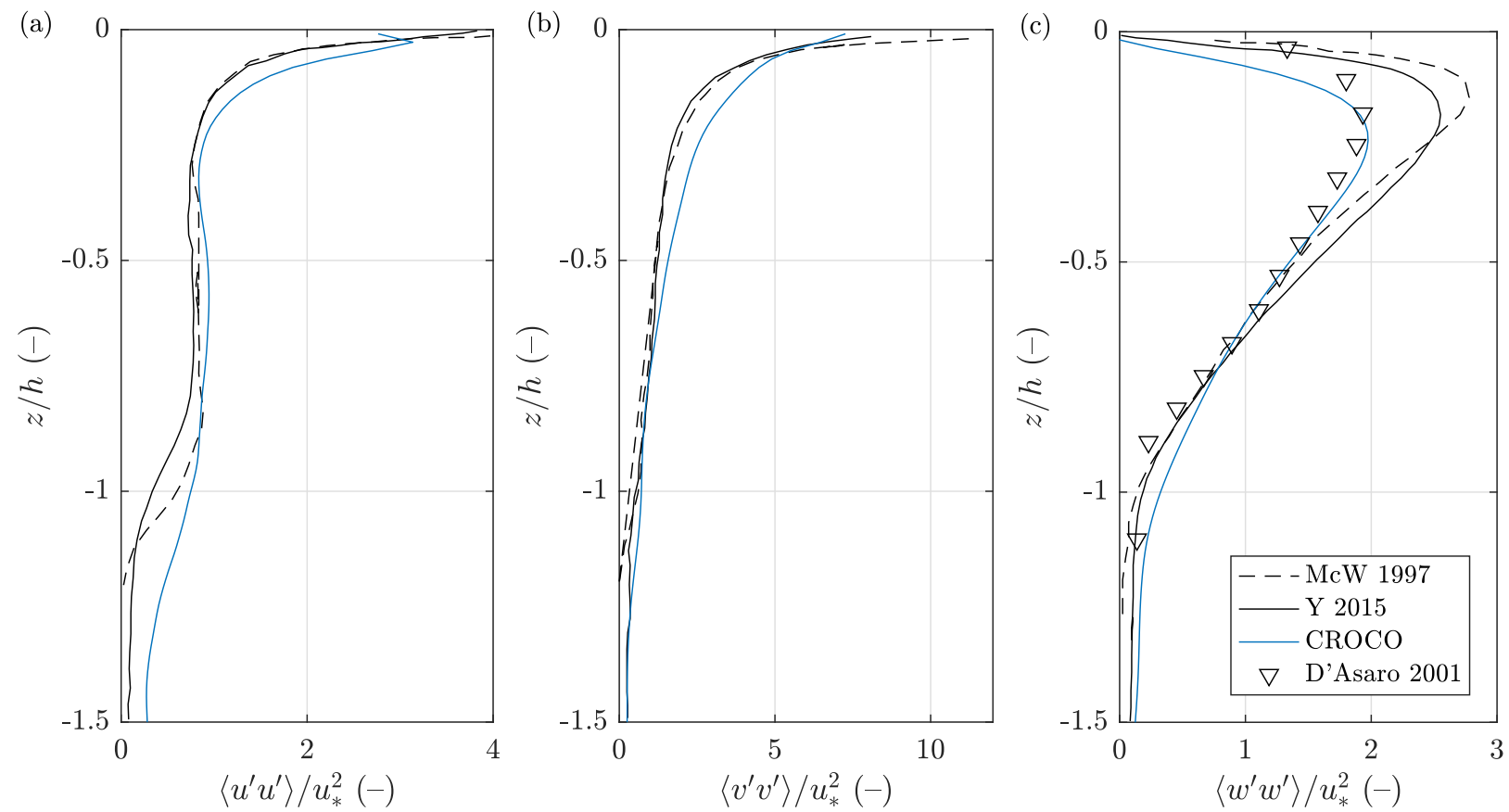

Figure S8: As in Fig. S6, but for $\left\langle u^{\prime} u^{\prime}\right\rangle / u_{\star}^{2}$ (a), $\left\langle v^{\prime} v^{\prime}\right\rangle / u_{\star}^{2}$ (b) and $\left\langle w^{\prime} w^{\prime}\right\rangle / u_{\star}^{2}$ (c). In (c), triangle symbols show $\left\langle w^{\prime} w^{\prime}\right\rangle / u_{\star}^{2}$ obtained from measurements in the open ocean by D'Asaro (2001). 


\section{Section S4. Time evolution of domain-averaged frazil concentration profiles}

Figure S9 shows examples of time series of the domain-averaged vertical profiles of frazil volume fraction from two simulations from Series $\mathcal{F}_{0}$. The data analysis presented in the paper is based on results from hours $7-18$ (to the right of the dashed lines in the figure).
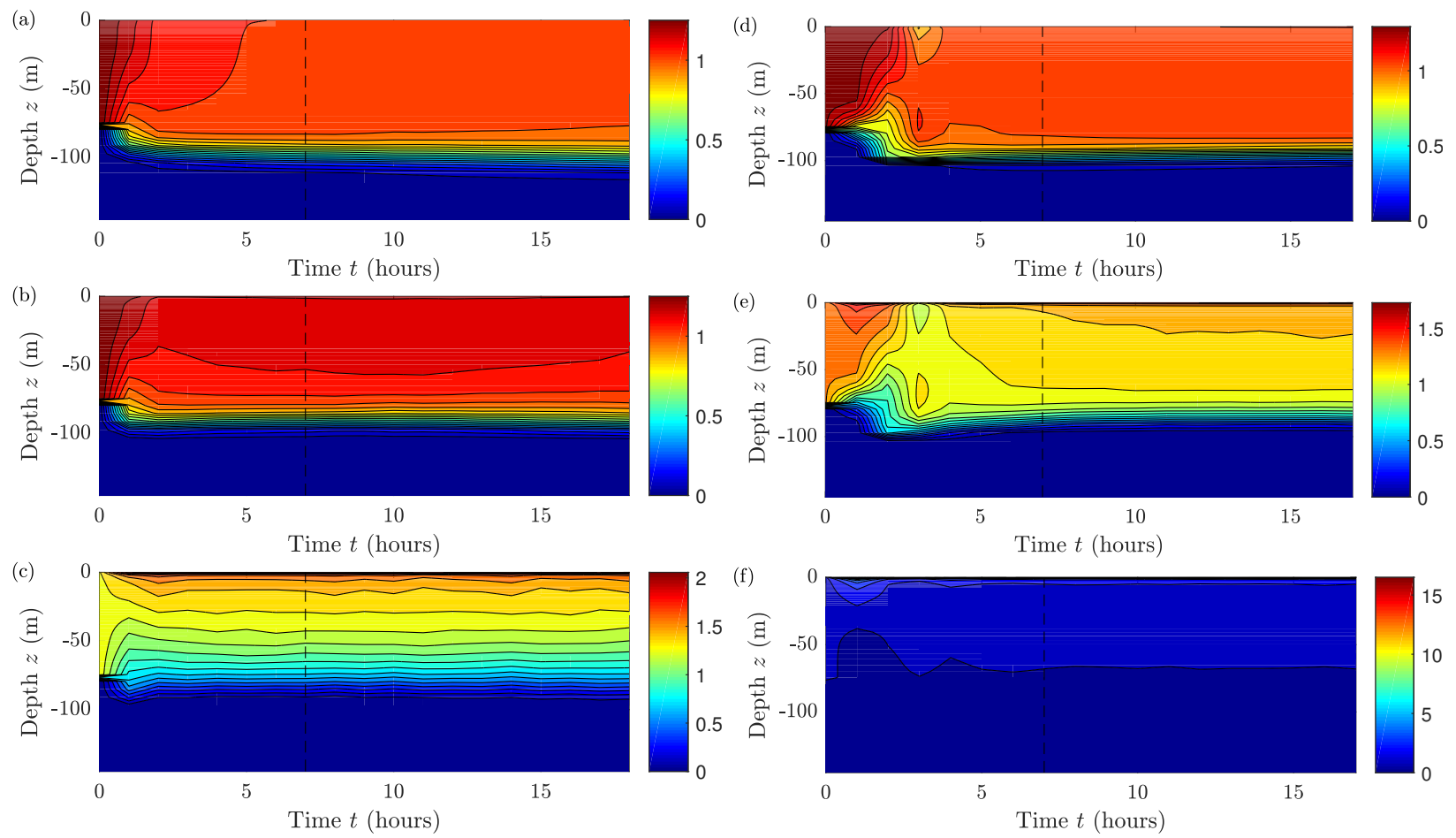

Figure S 9: Time evolution of the domain-averaged vertical profiles of frazil size fractions $c_{1} / \tilde{c}_{1}(\mathrm{a}, \mathrm{d})$, $c_{2} / \tilde{c}_{2}(\mathrm{~b}, \mathrm{e})$ and $c_{3} / \tilde{c}_{3}(\mathrm{c}, \mathrm{f})$ in simulations with $U_{a}=30 \mathrm{~m} / \mathrm{s}, T_{a}=-1.5^{\circ} \mathrm{C}(\mathrm{a}-\mathrm{c})$ and $U_{a}=5 \mathrm{~m} / \mathrm{s}, T_{a}=-20^{\circ} \mathrm{C}$ (d-f) from series $\mathcal{F}_{0}$. Dashed lines at $t=7$ hours mark the time when the result analysis starts. Note different color scales in the panels. 


\section{Section S5. The influence of domain size on modelling results}

In order to test the influence of the model domain size on the modelling results, one of the forcing scenarios analyzed in the main text $\left(U_{a}=15 \mathrm{~m} / \mathrm{s}\right.$ and $\left.T_{a}=-1.5^{\circ} \mathrm{C}\right)$ has been run on a large domain, $2400 \times 2400 \mathrm{~m}^{2}$ in size (as compared to $1200 \times 1200 \mathrm{~m}^{2}$ in the case of the 'standard' domain). The results are compared in Figs. S10-S12.

(a)

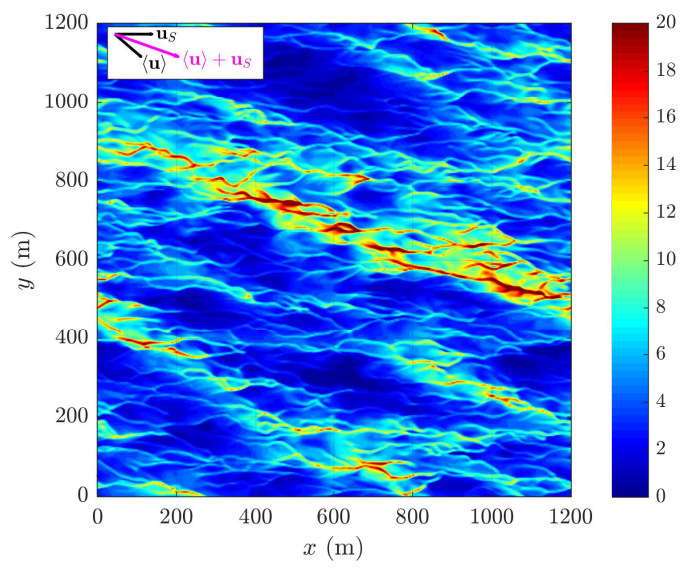

(b)

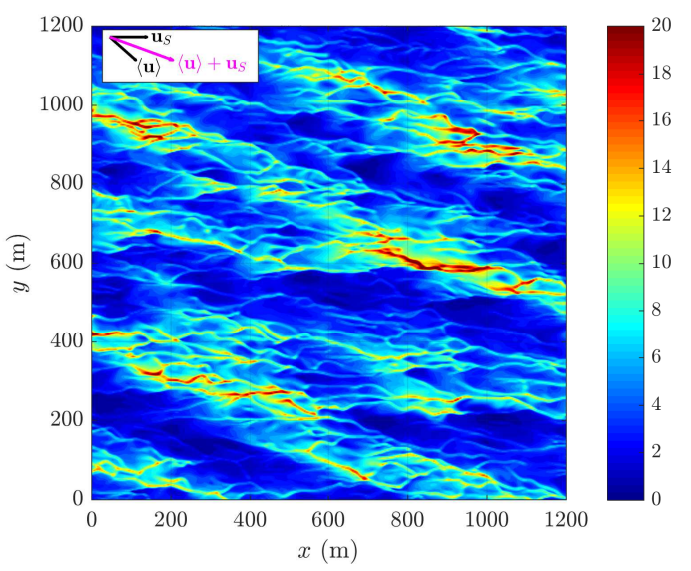

(c)

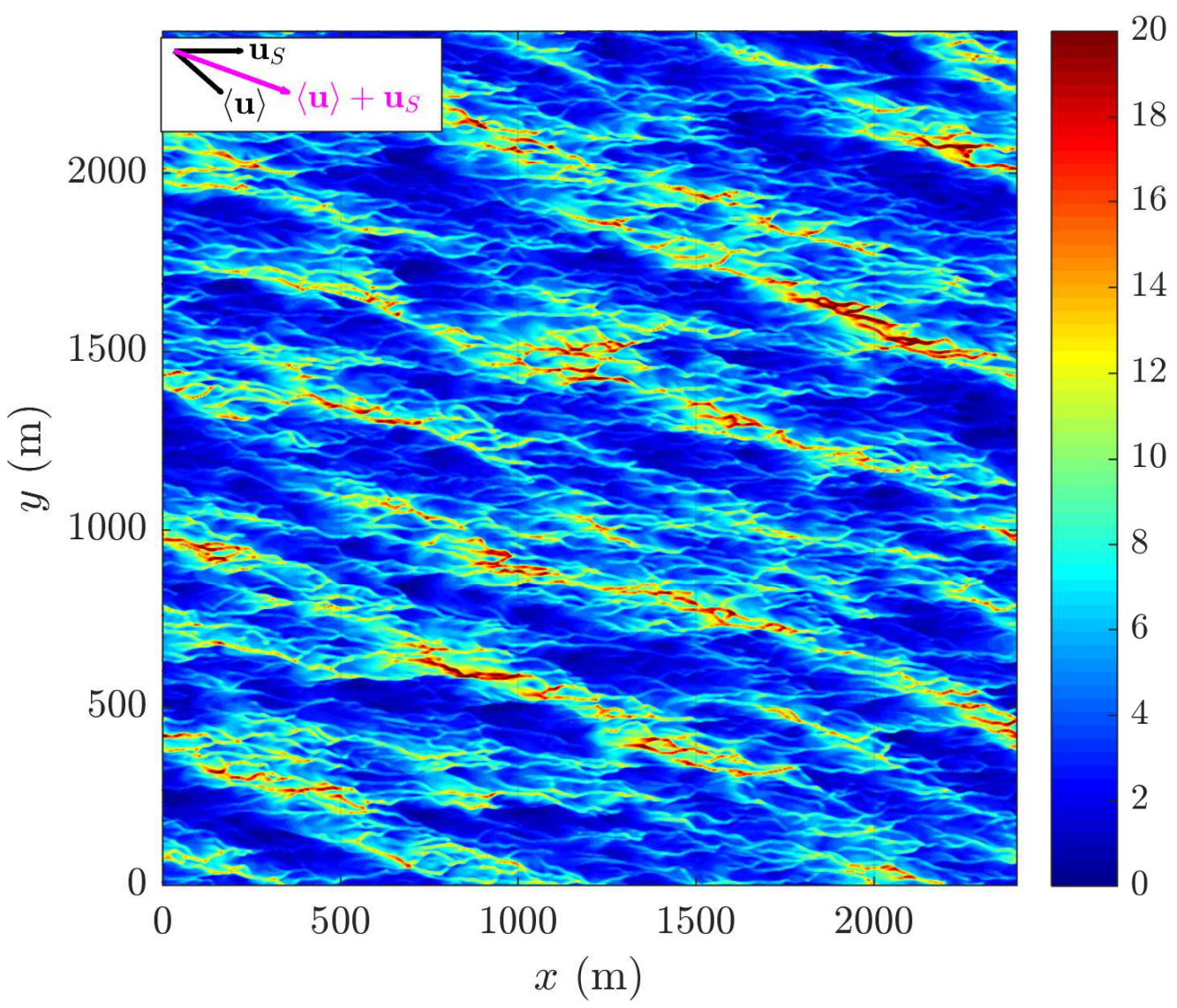

Figure S10: Surface concentration of the frazil class 3 in simulations with $U_{a}=15 \mathrm{~m} / \mathrm{s}$ and $T_{a}=-1.5^{\circ} \mathrm{C}$ : 'small' model domain, used in all simulations analyzed in the main text (a), and 'large' model domain with size $2400 \times 2400 \mathrm{~m}^{2}$ (c). In (b), a fragment of (c) is shown the same size as in (a). 


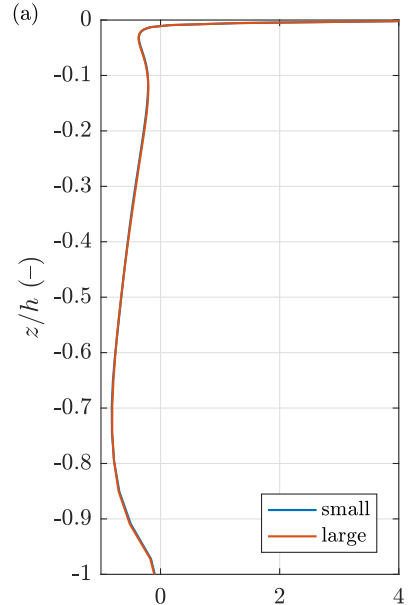

$\langle\bar{u}\rangle / u_{*}{ }^{(-)}$

(e)

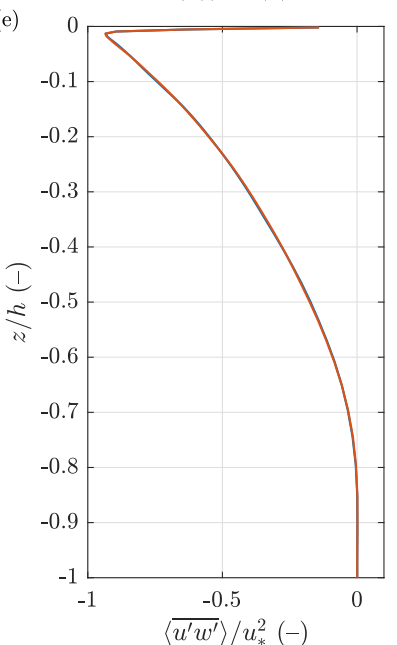

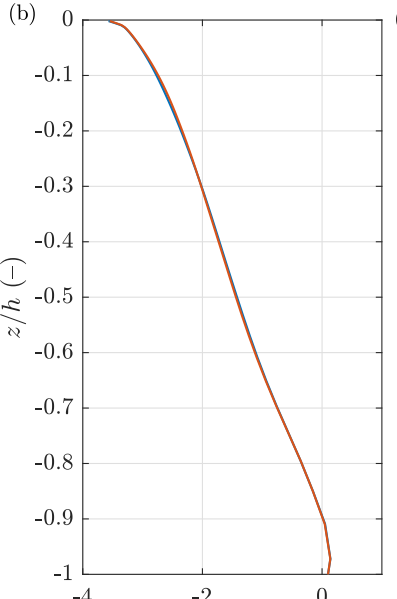

$\langle\bar{v}\rangle / u_{*}(-)$

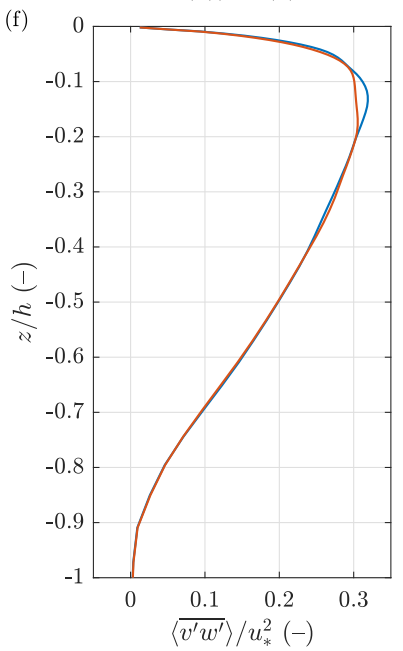

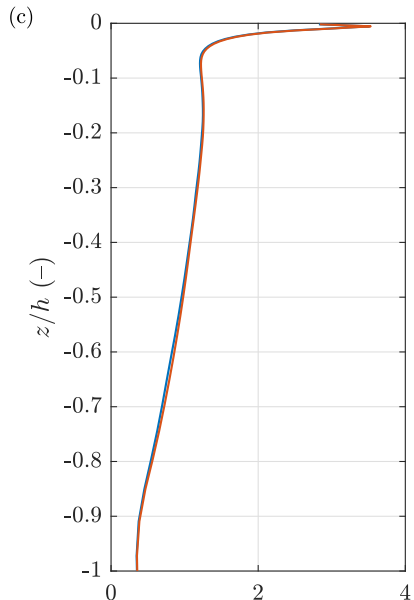

$\left\langle\overline{u^{\prime} u^{\prime}}\right\rangle / u_{*}^{2}{ }^{(-)}$

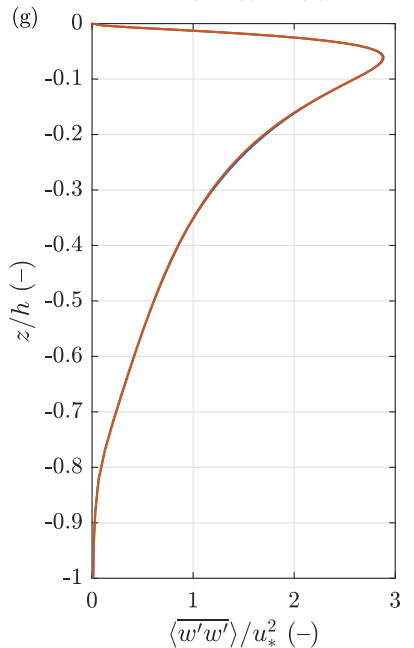

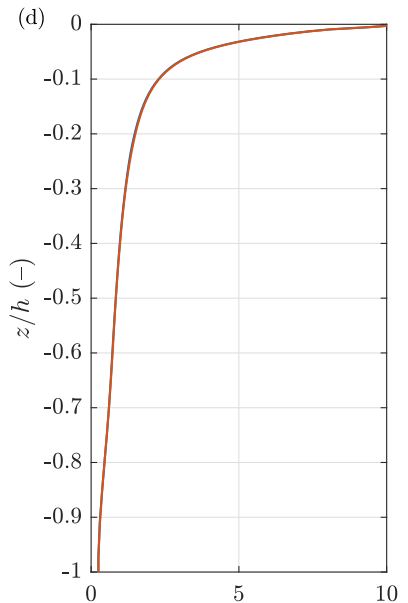

$\left\langle\overline{v^{\prime} v^{\prime}}\right\rangle / u_{*}^{2}(-)$

Figure S11: Vertical profiles of the mean velocity $(\mathrm{a}, \mathrm{b})$, momentum flux $(\mathrm{e}, \mathrm{f})$ and velocity variance $(\mathrm{c}, \mathrm{d}, \mathrm{g})$ for the small (blue) and large (red) domain. Results of simulations without frazil coupling (series $\mathcal{F}_{0}$ ). All values are normalized with the respective friction velocity $u_{*}$. 


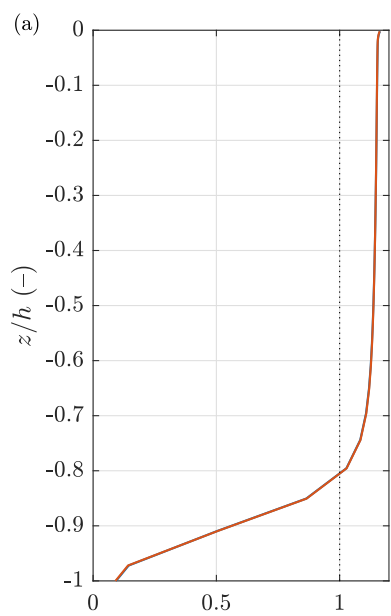

$\left\langle\bar{c}_{1}\right\rangle / \tilde{c}_{1}(-)$

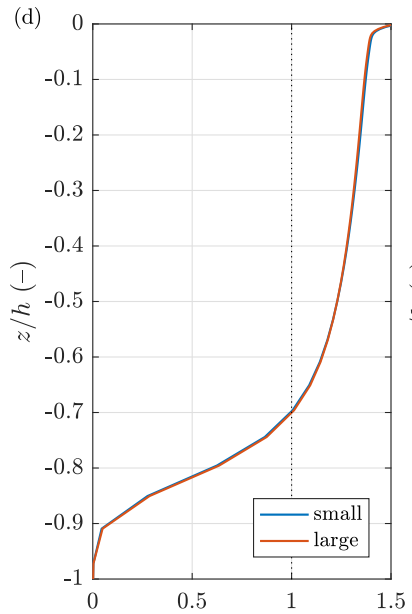

$\left\langle\bar{c}_{2}\right\rangle / \tilde{c}_{2}(-)$

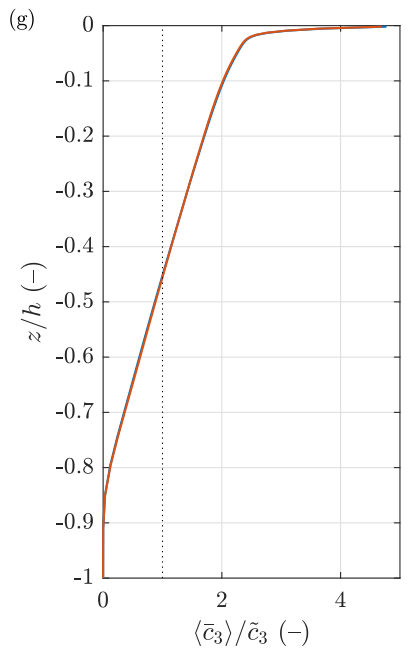

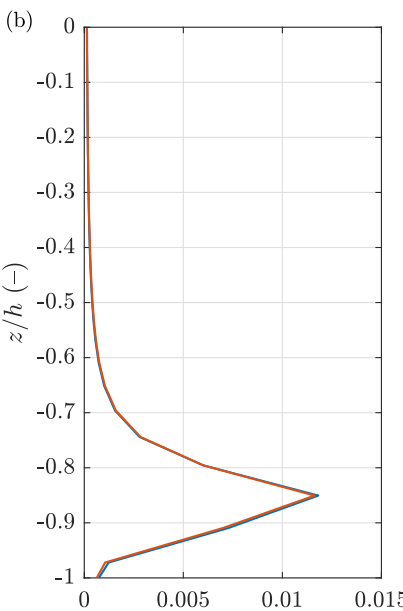

$\left\langle\overline{\left\langle c_{1}^{\prime} \prime_{1}^{\prime}\right.}\right\rangle / \tilde{c}_{1}^{2}(-)$
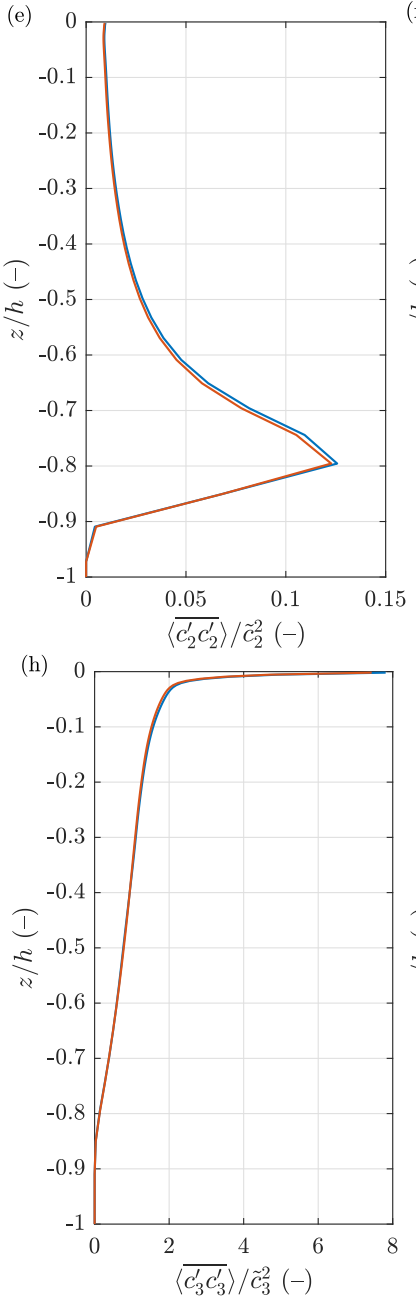
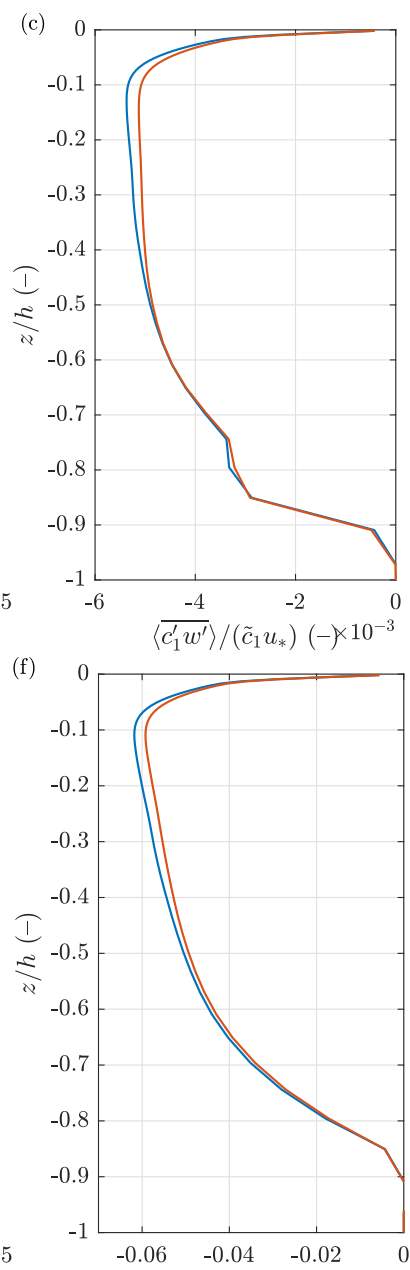

$\left\langle\overline{c_{2}^{\prime} w^{\prime}}\right\rangle /\left(\tilde{c}_{2} u_{*}\right)(-)$

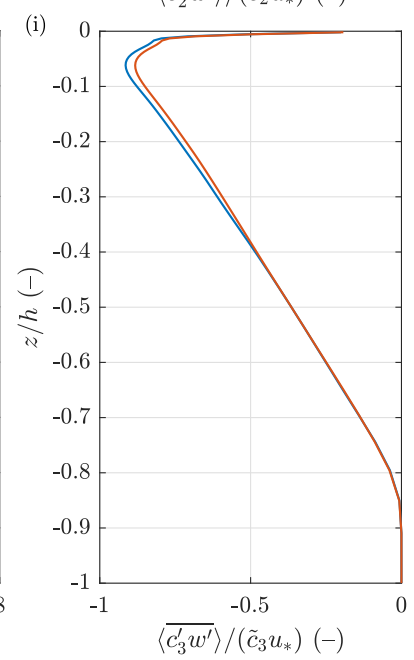

Figure S12: Vertical profiles of the mean $(\mathrm{a}, \mathrm{d}, \mathrm{g})$, variance $(\mathrm{b}, \mathrm{e}, \mathrm{h})$ and vertical flux $(\mathrm{c}, \mathrm{f}, \mathrm{i})$ of the frazil volume fraction for size classes 1-3 for the small (blue) and large (red) domain. Note different $x$ axis ranges in the plots. 


\section{Section S6. The influence of latitude on modelling results}

All simulations described in the main text have bene performed with constant latitude $\phi=75^{\circ} \mathrm{N}$. In order to assess the influence of $\phi$ on the modelling results, one of the forcing scenarios analyzed in the main text $\left(U_{a}=15 \mathrm{~m} / \mathrm{s}\right.$ and $T_{a}=-1.5^{\circ} \mathrm{C}$; as in Section $\left.\mathrm{S} 5\right)$ has been run for two different values of $\phi, 60.0^{\circ} \mathrm{N}$ and $82.5^{\circ} \mathrm{N}$. The results are compared in Figs. S13-S15.

Notably, the amplitude and direction of the surface current in both cases differ by less than $0.01 \mathrm{~m} / \mathrm{s}$ and $1^{\circ}$, respectively, explaining the very similar orientation of the frazil streaks at both latitudes.

Although there are differences in the vertical profiles of the mean horizontal velocity components, the vertical profiles of the mean frazil concentration are essentially identical - a manifestation of the fact that they are predominantly shaped by smaller-scale details of Langmuir turbulence.

(a)

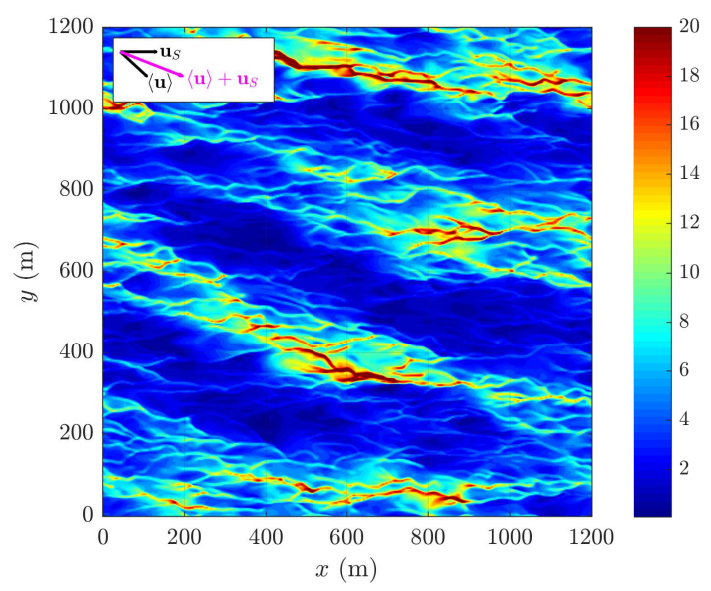

(b)

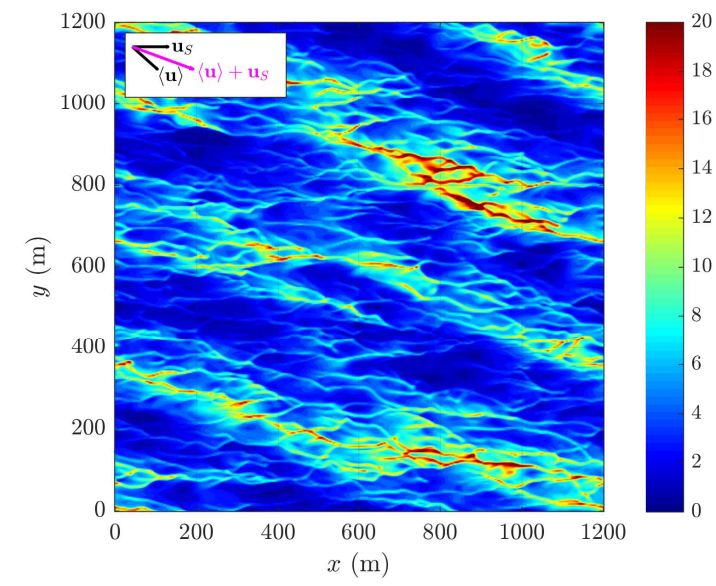

Figure S13: Surface concentration of the frazil class 3 in simulations with $U_{a}=15 \mathrm{~m} / \mathrm{s}$ and $T_{a}=-1.5^{\circ} \mathrm{C}$, with $\phi=60.0^{\circ} \mathrm{N}(\mathrm{a})$ and $\phi=82.5^{\circ} \mathrm{N}(\mathrm{b})$. 


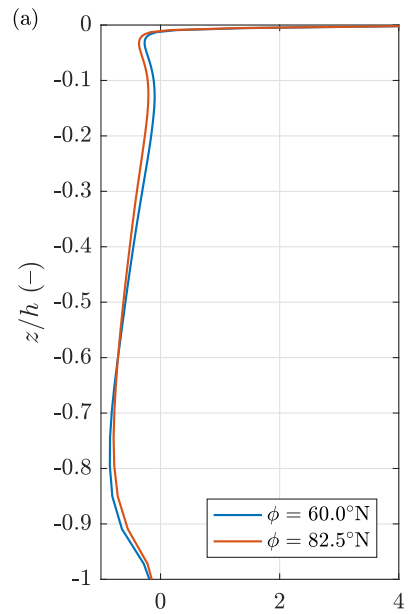

$\langle\bar{u}\rangle / u_{*}(-)$

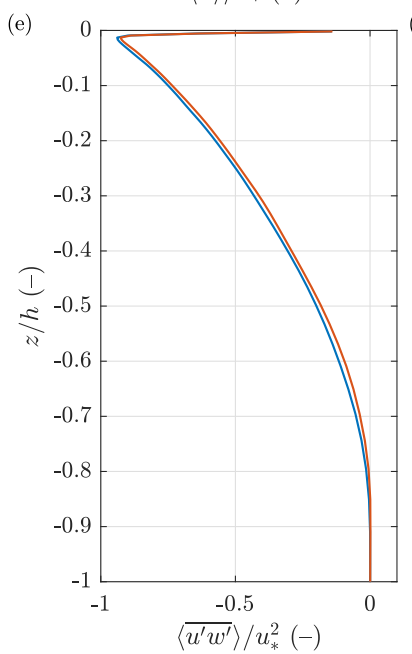

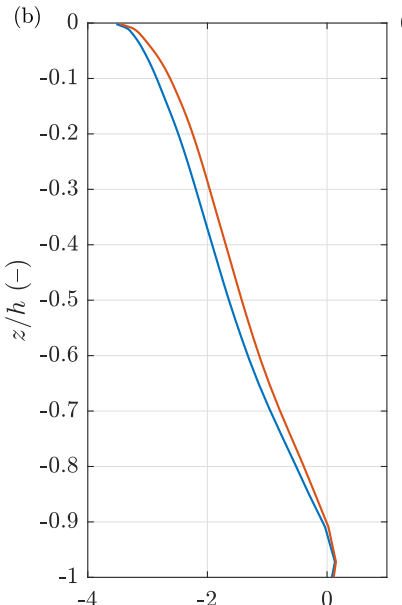

$\langle\bar{v}\rangle / u_{*}(-)$

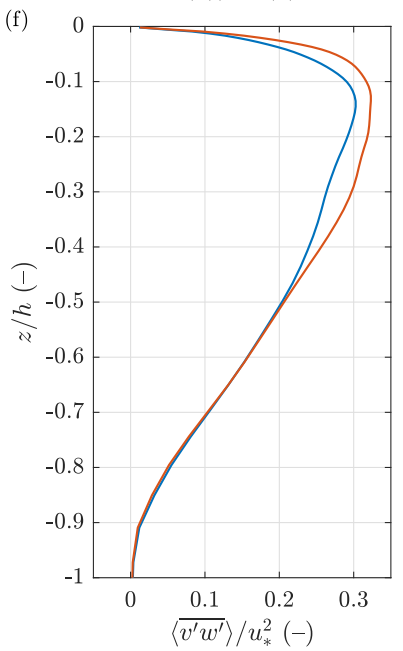

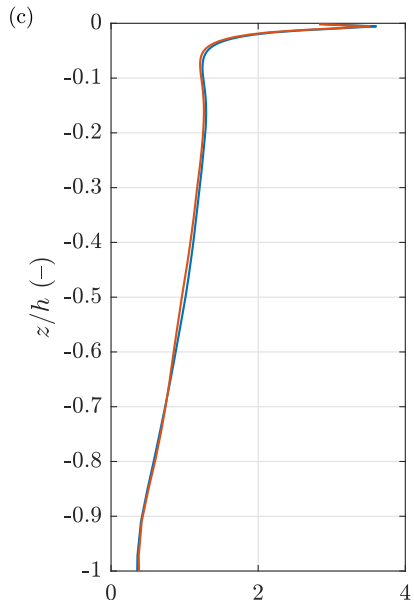

$\left\langle\overline{u^{\prime} u^{\prime}}\right\rangle / u_{*}^{2}(-)$

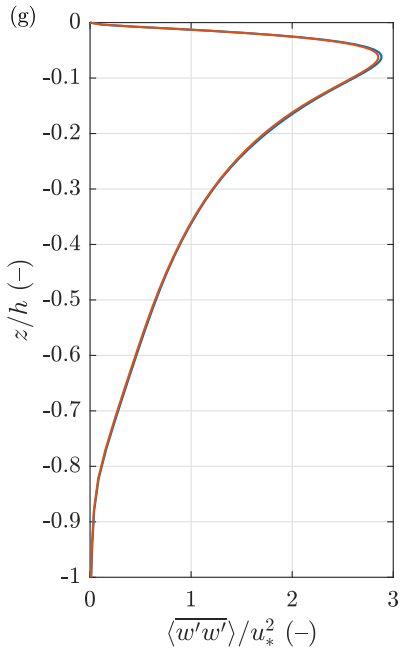

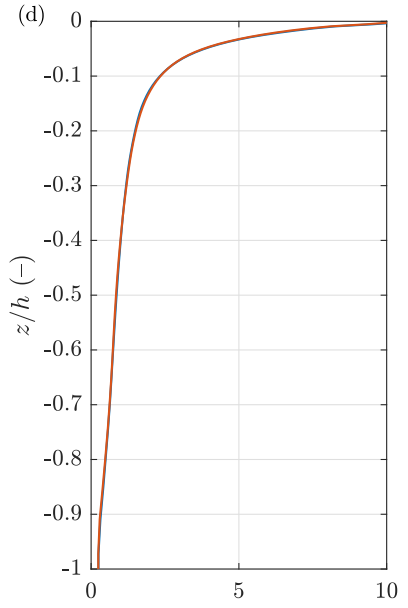

$\left\langle\overline{v^{\prime} v^{\prime}}\right\rangle / u_{*}^{2}(-)$

Figure S14: Vertical profiles of the mean velocity $(\mathrm{a}, \mathrm{b})$, momentum flux (e,f) and velocity variance $(\mathrm{c}, \mathrm{d}, \mathrm{g})$ for $\phi=60.0^{\circ} \mathrm{N}$ (blue) and $\phi=82.5^{\circ} \mathrm{N}$ (red). Results of simulations without frazil coupling (series $\mathcal{F}_{0}$ ). All values are normalized with the respective friction velocity $u_{*}$. 


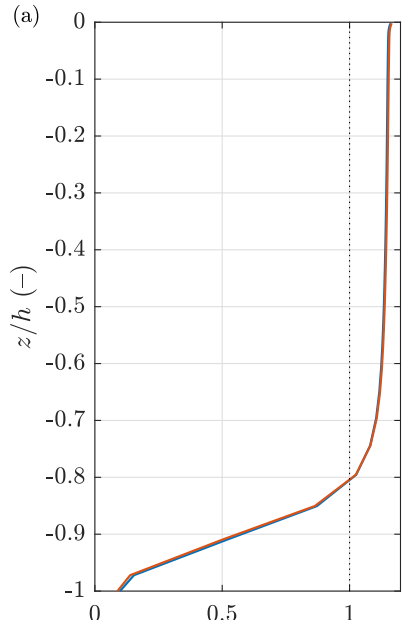

$\left\langle\bar{c}_{1}\right\rangle / \tilde{c}_{1}(-)$

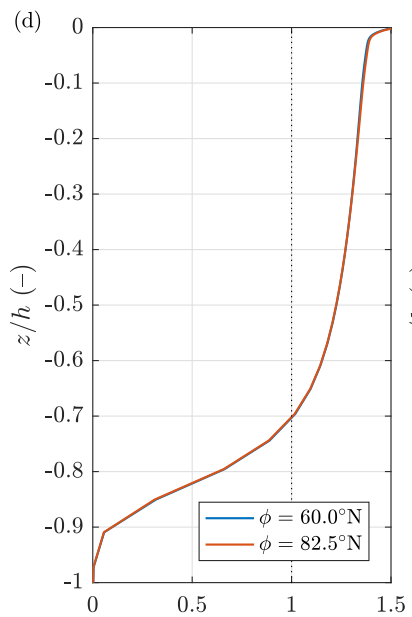

$\left\langle\bar{c}_{2}\right\rangle / \tilde{c}_{2}(-)$

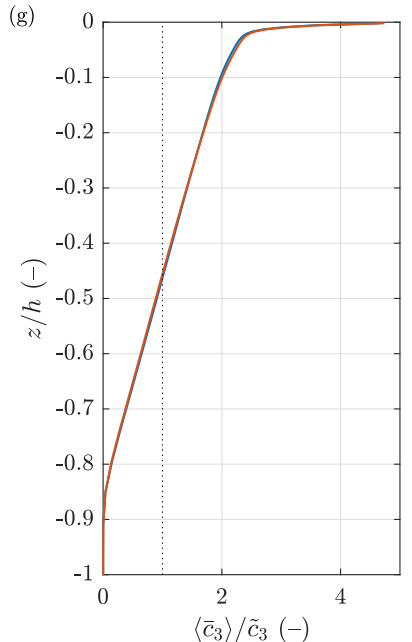

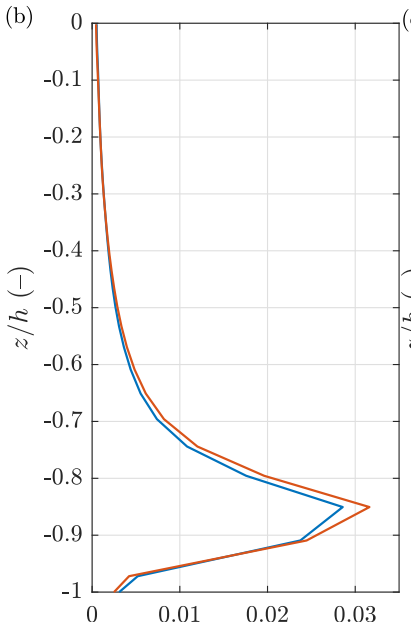

$\left\langle\overline{c_{1}^{\prime} c_{1}^{\prime}}\right\rangle / \tilde{c}_{1}^{2}(-)$

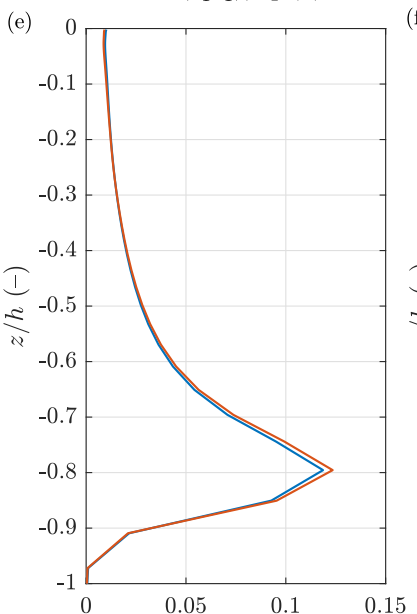

$\left\langle\overline{c_{2}^{\prime} c_{2}^{\prime}}\right\rangle / \tilde{c}_{2}^{2}(-)$

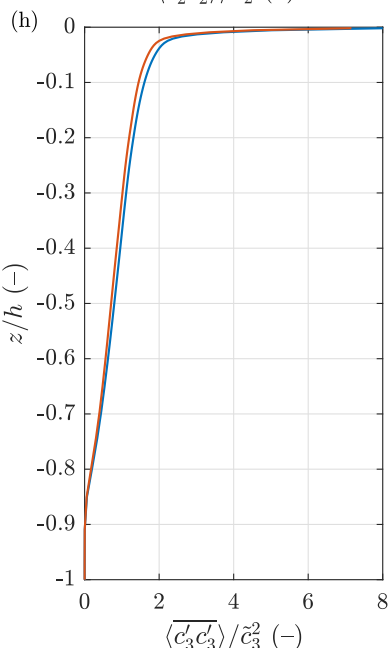

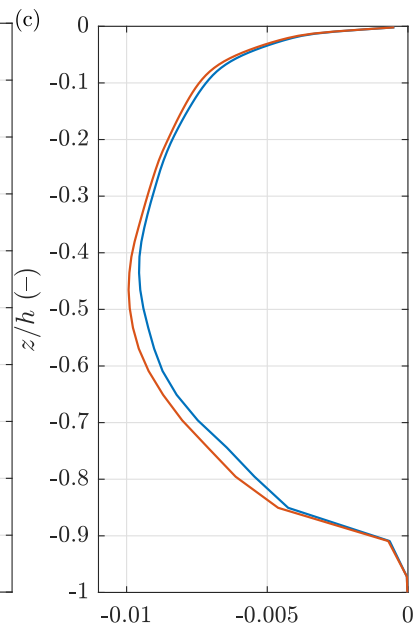

$\left\langle\overline{c_{1}^{\prime} w^{\prime}}\right\rangle /\left(\tilde{c}_{1} u_{*}\right)(-)$

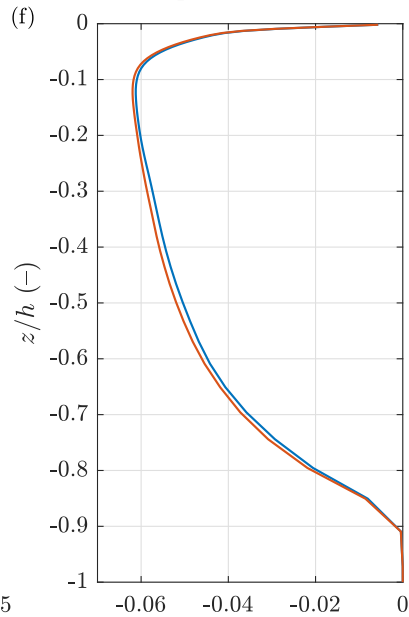

$\left\langle\overline{c_{2}^{\prime} w^{\prime}}\right\rangle /\left(\tilde{c}_{2} u_{*}\right)(-)$

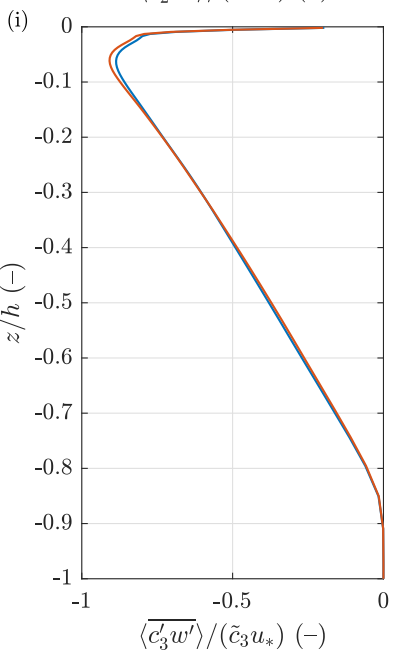

Figure S15: Vertical profiles of the mean (a,d,g), variance (b,e,h) and vertical flux (c,f,i) of the frazil volume fraction for size classes 1-3 for for $\phi=60.0^{\circ} \mathrm{N}$ (blue) and $\phi=82.5^{\circ} \mathrm{N}$ (red). Note different $x$ axis ranges in the plots. 
Section S7. Selected details of simulations with $U_{a}=30 \mathrm{~m} / \mathrm{s}, T_{a}=$ $-20^{\circ} \mathbf{C}$, series $\mathcal{F}_{0}$

Figures in this section are analogous to those presented in Figs. 11-13 in the main text, but they present results from series $\mathcal{F}_{0}$ instead of $\mathcal{F}_{\text {all }}$.
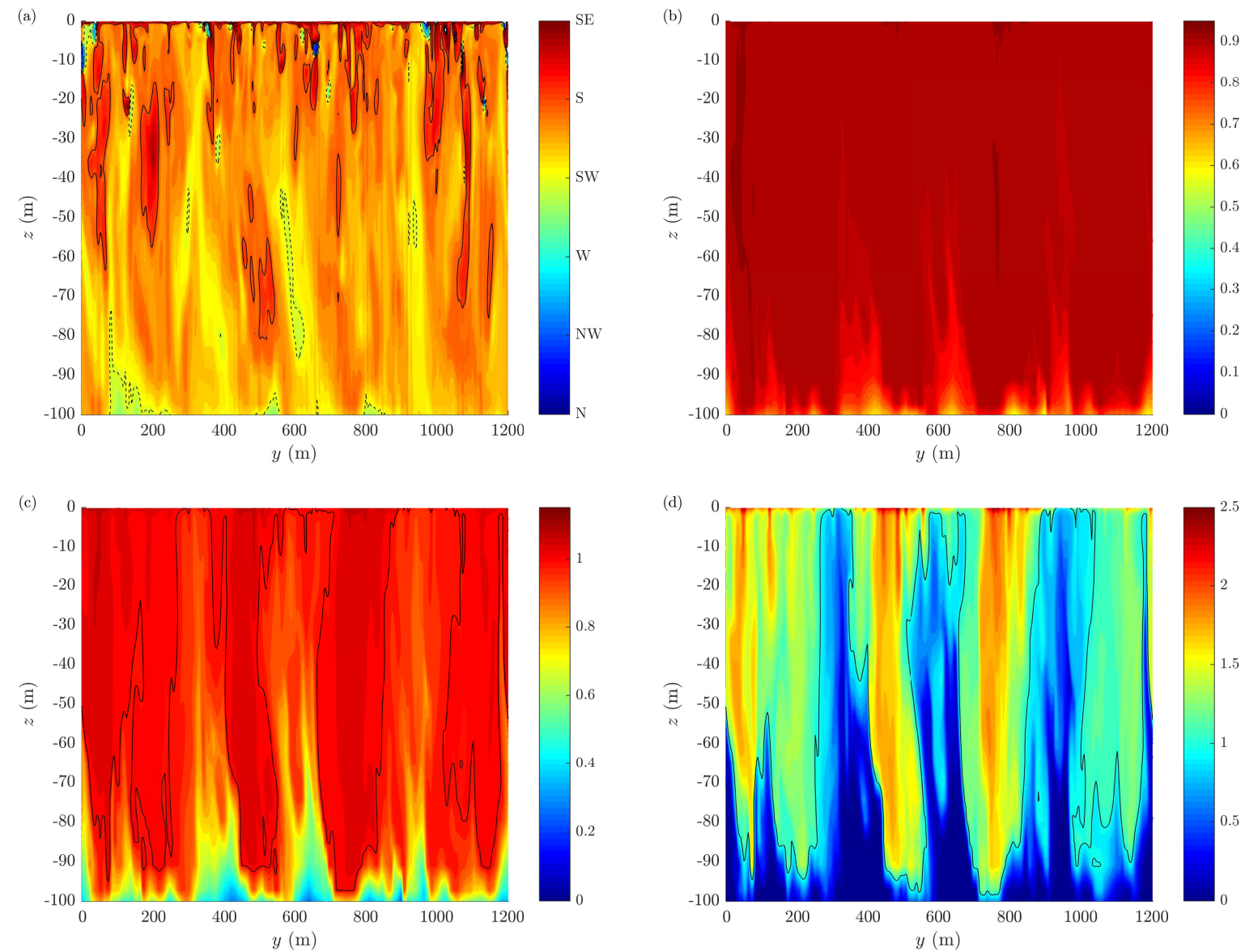

Figure S16: Direction of the horizontal flow (a) and frazil volume fraction $c_{i} / \tilde{c}_{i}(\mathrm{~b}-\mathrm{d})$ along a cross-section through the model domain perpendicular to the wind/wave direction. In (a), a 'to'-convention is used, i.e., S means current flowing to the south and so on. In (b)-(d), black contours show the value of 1 . Results of simulations with $U_{a}=30 \mathrm{~m} / \mathrm{s}, T_{a}=-20^{\circ} \mathrm{C}$, series $\mathcal{F}_{0}$. 


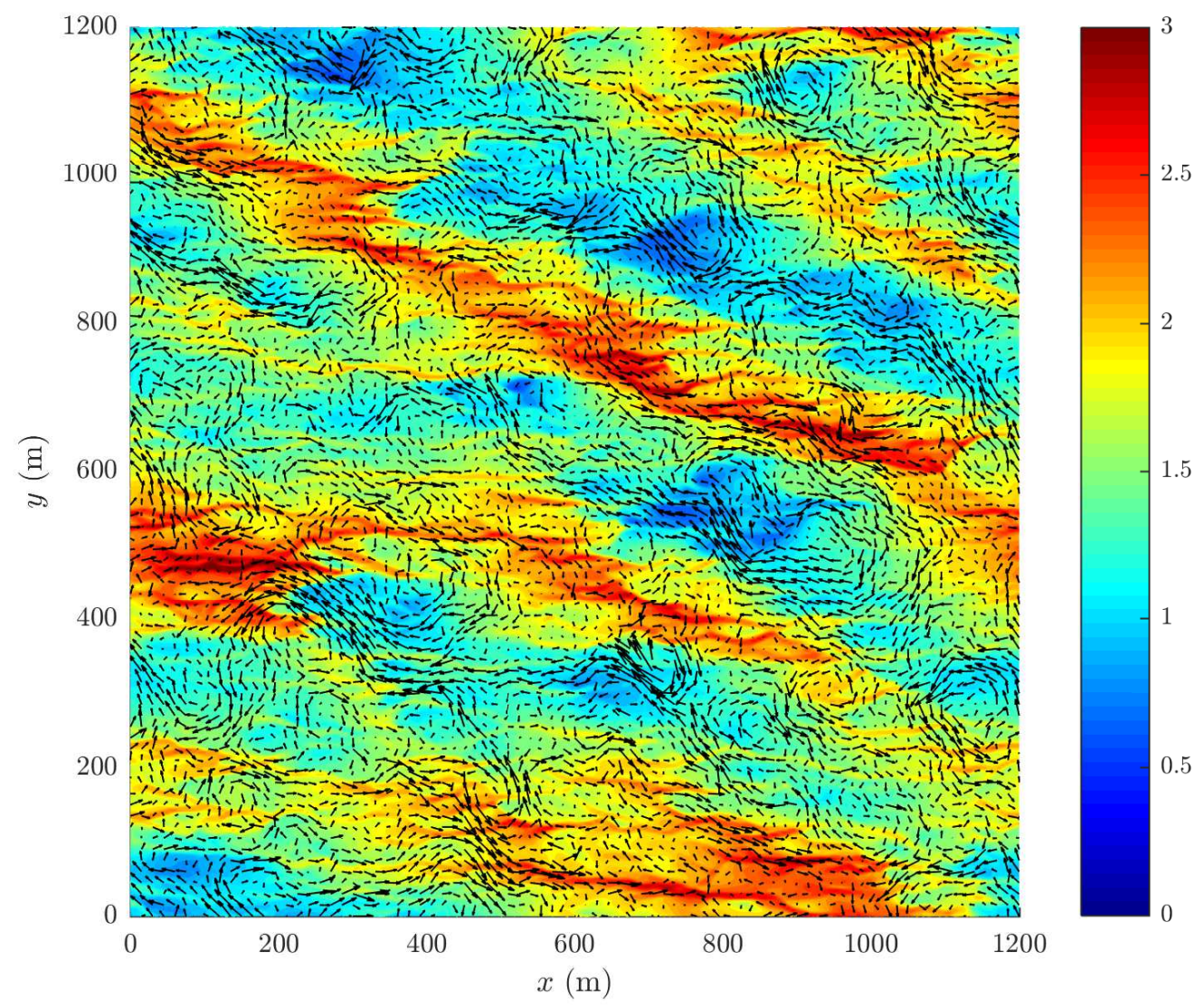

Figure S17: Volume fraction of the largest frazil size class $c_{3} / \tilde{c}_{3}$ at the sea surface (colour) and anomalies of the vertically integrated horizontal currents (arrows) in simulations with $U_{a}=30 \mathrm{~m} / \mathrm{s}, T_{a}=-20^{\circ} \mathrm{C}$, series $\mathcal{F}_{0}$. For better visibility, only every 5 th arrow in each direction has been plotted.

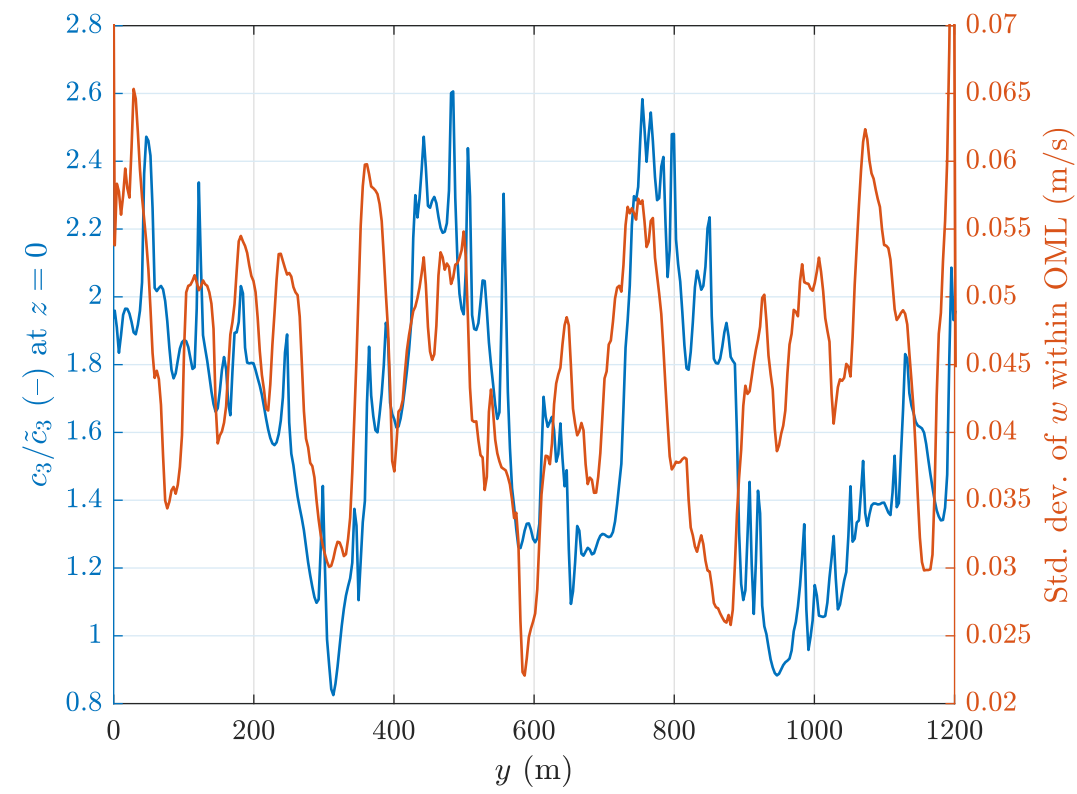

Figure S18: Volume fraction of the largest frazil size class $c_{3} / \tilde{c}_{3}$ at the surface (left axis) and standard deviation of the vertical velocity $w$ within the OML (right axis) in the same situation as shown in Fig. S16. 


\section{References}

D'Asaro, E.: Turbulent vertical kinetic energy in the ocean mixed layer, J. Phys. Oceanogr., 31, 3530-3537, https://doi.org/10.1175/1520-0485(2002)031;3530:TVKEIT;2.0.CO;2, 2001.

Holthuijsen, L.: Waves in oceanic and coastal waters, Cambridge Univ. Press, 387 pp., 2007.

Kondo, J.: Air-sea bulk transfer coefficients in diabatic conditions, Boundary Layer Meteorol., 9, 91-112, https://doi.org/10.1007/BF00232256, 1975.

Li, M., Garrett, C., and Skyllingstad, E.: A regime diagram for classifying turbulent large eddies in the upper ocean, Deep-Sea Res. I, 52, 259-278, https://doi.org/10.1016/j.dsr.2004.09.004, 2005.

Massel, M.: Ocean Surface Waves: Their Physics and Prediction, World Scientific, 690 pp., 2013.

McWilliams, J., Sullivan, P., and Moeng, C.-H.: Langmuir turbulence in the ocean, J. Fluid Mech., 334, 1-30, https://doi.org/10.1017/S0022112096004375, 1997.

Yang, D., Cheng, B., Chamecki, M., and Meneveau, C.: Oil plumes and dispersion in Langmuir, upper-ocean turbulence: Large-eddy simulations and K-profile parameterization, J. Geophys. Res., 120, 4729-4759, https://doi.org/10.1002/2014JC010542, 2015. 